\title{
Organisation of industry and innovation dynamics*
}

\author{
Tommaso Ciarli ${ }^{\dagger}$ \\ Riccardo Leoncini ${ }^{\ddagger}$ \\ Sandro Montresor ${ }^{\S}$ \\ Marco Valente
}

Revised version: ISS Proceedings

October 102006

\begin{abstract}
The paper aims at investigating how the organization of a certain industry evolves once the competition among its firms, producing a 'complex' (i.e. non-modular) product, is modeled as the intertwining of innovative search and organizational change. In order to take the full roster of participants into account, and to retain the inner complexity of their decisions, a Pseudo-NK model is built-up in which a population of firms is called to match a technological frontier. By evolving along different stages of the sector's life-cycle, such a kind of technological calls for a trade-off between two strategies of cost-reduction through either outsourcing or technological search. Overall, the simulation results confirm previous literature as, for example, in the introductory stage of the industry life-cycle, marked by frequent and intense jumps of the technological frontier, firms need to vertically integrate in order to have higher chances to win the competition for a new standard. On the contrary, in the decline stage, in which the technological frontier almost stabilizes, deverticalization allows firms to better compete on costs. These results change if suppliers are allowed to innovate, as they are more likely to lock the market in sub-optimal configurations.
\end{abstract}

\footnotetext{
* A previous version of the paper, titled "The Organisation of Industry in a Modular World: Some Insights form a Pseudo-NK Model", has been presented at the Wehia 2006, $1^{\text {st }}$ International Conference on 'Economic Sciences with Heterogeneous Interacting Agents', Bologna; the International Schumpeter Society $11^{t h}$ ISS Conference on 'Innovation, Competition and Growth: Schumpeterian Perspectives', Sophia-Antipolis; and the SPRU $40^{\text {th }}$ Anniversary Conference on 'The Future of Science, Technology and Innovation Policy', Sussex. We acknowledge conferences participants for helpful comments and critiques, in particular Robin Cowan, Gerald Siverberg and Bo Carlsson. Leoncini and Montresor also acknowledge the financial support of the PRIN project 'Fragmentation and Local Development', University of Bologna. Usual disclaimer on author's own responsibility applies.

†University of L'Aquila and University of Bologna, tommaso.ciarli@unibo.it

$\ddagger$ University of Bologna, riccardo.leoncini@unibo.it

$\S$ University of Bologna, montreso@spbo.unibo.it

ฯ University of L'Aquila, valente@ec.univaq.it
} 


\section{Introduction}

It is now a well established result that technological and organizational change constantly interact in shaping the division of labor between and within firms, and thus the organization of an industry. Not only is technological competition among firms a crucial determinant of the dynamics of industries in terms of market concentration and market behavior, not to say of rate of entry, survival and growth of firms (Klepper 2002, Klepper and Simons 2000), but changes in the firm's organizational arrangements, such as vertical integration and disintegration strategies, also affect their innovative outcomes (e.g. Robertson and Langlois 1995). Moreover, both technological and organizational changes are affected by the degree of complexity of, respectively, the product and the organization. Non-modularity (Brusoni and Prencipe 2001, Langlois 1992), for example, poses to the firms' process of change such complex constraints, that they can just try to do it heuristically, by searching for satisfactory, rather than optimal solutions.

On the basis of these arguments, the paper aims at showing that the organization of an industry can be seen as the emergent property of a complex process of search and competition, in which the vertical scope of the firms co-evolve with, rather than simply determine, their innovative behavior. In order to do so, the overall institutional structure of an industry, and its changes over time, are related to the firms' individual behaviors by building up an agent-based model with three specific characteristics.

First of all, we refer to an industry populated by a number of firms differing in both the capabilities to follow the technological frontier of their product and the transaction costs they face if they decide to outsource some production components. This allows us to provide a sound micro-foundation to the changes occurring in the industry organization. Indeed, if all the firms of one industry were good both upstream and downstream, no one of them would find convenient to specialize, regardless of the potential transaction costs. On the contrary, if firms differ in terms of capabilities, and the entailed specialization economies outweigh the bundle of transaction costs, vertical disintegration becomes convenient.

Second, firms are engaged in producing a final good, made up of production components, which affect the characteristics demanded by the consumers. Keeping the production modules in house, that is being vertically integrated, firms can rely on their R\&D department and try to match the evolution of the technological frontier. Outsourcing the production modules to external specialized suppliers, instead, allows final firms to obtain them in a more economic way, but loosing the chance of ameliorating their technology. This allows us to fit the organizational and the technological decisions of the firms in a trade-off they face between the static efficiency guaranteed by a reduction in transaction costs, and the dynamic one given by a superior technological performance.

Third, the final good produced by the firms is weakly modular, so that a technological change in a production module brings with it a pervasive set of changes in many of the others. In so doing we are able to retain the complexity of the firms' innovative and organizational decisions, and the fact that it often leads them to sub-optimal results.

By simulating the model we aim at obtaining, as emergent properties, 'aggregated' results for the organization of the industry, to be possibly compared 
with those obtained by other contributions trough case-studies and more qualitative analyses. Among the others, we are interested in relating our results to those obtained in two strands of research. First of all, we aim at investigating whether our results support or not the dominant view in the studies on the relationship between vertical scope and technological change. Second, we aim at checking whether our model replicates or not the results obtained by investigating the evolution of the innovative behavior and of the market structure along the life-cycle of a sector.

The structure of the paper is the following. Section 2 will briefly illustrate the theoretical background of the paper. Section 3 will detail the rationale and the functioning of the model. Section 4 will organize the simulation results around the two issues we are interested in. Section 5 will conclude.

\section{Innovation and the organization of industry: the need of a complex approach}

Given the complexity of the issue addressed by the paper, its theoretical and methodological background is somehow eclectic. More precisely, four are the research lines on which the paper draws.

First of all, an integrated approach to the determinants of the institutional structure of an industry, combining transaction costs and capabilities, is adopted. The "organization of industry", once retained mainly an issue of price and quality competition (Stigler 1968), is increasingly more related to the governance of the firms' transactions (Williamson 1975) and to the production and innovative capabilities of the firms (Richardson 1972). In spite of the differences between the two paradigms, an integrated approach to the issue has been recently recommended (Williamson 1999, Nooteboom 2004). In particular, it has been argued that the distribution of production capabilities in the relevant industry should be an explanand, along with transaction costs, of its organizational and technological changes (Jacobides and Winter 2005).

In sticking to this combined approach, heterogeneity in production capabilities is crucial in supplying, along with transaction costs, an engine to the organization of industry and to its dynamics. This emerges clearly when the 'black-box' of the production function gets unpackaged and production techniques within it can only be searched and chosen by evaluating the firm's fitness to the outer technological landscape (Kauffman, Lobo, and Macready 2000).

This is the second starting point of the paper. Following the evolutionary perspective, we maintain that firms deal with innovation activities, as well as with production, as bounded rational agents, resorting to research heuristics, rather than to optimal procedures. The (local) knowledge embedded in the organisational routines of the firms (Nelson and Winter 1982), and the capabilities and competencies to set it at work in problem-solving activities (Dosi, Nelson, and Winter 2000), constitute accordingly a basic ingredient of our methodological approach to the issue. This is the more so when we refer, as we do in the paper, to firms which are engaged in 'complex products and systems', such as "tailored capital goods, systems constructs and services" (Dosi, Hobday, and Marengo 2000, p. 5). In these cases, the decision process actually becomes complex and requires firms to draw on special cognitive models. 
Indeed, the third starting point of the paper is represented by a "Simonian" perspective to the solution of complex problems. Accordingly, we maintain that both the technological and the organizational changes the firms undertake are often very complex. The number and variety of the dimensions of each problem of change, together with the interactions among the dimensions, are so high that the problem necessarily requires a decomposition into sub-problems. Subproblems are then solved independently adding another dimension to solvers boundaries (Simon 1969). The way in which a new problem (e.g. innovation) is posed - decomposed - and the structure of the related (collective) problemsolving activity, therefore define another basic ingredient of our approach to the firm's innovative dynamics (Marengo, Dosi, Legrenzi, and Pasquali 2000). An element which appears indeed essential when the 'decomposability' problem emerges from the modular structure of the products the firm forges and of the organizational structure it adopts in doing it.

The fourth starting point of the paper is in fact represented by the growing literature on the issue of 'modularity' (Brusoni and Prencipe 2001). In fact, the interrelations among the elements of a complex problem may be translated into different economic dimensions: (i) a product with a modular (rather than an integrated) architecture; (ii) an innovation in the core design concepts (rather than in the architectural knowledge) of a certain product; (iii) an organization whose 'information' and 'compensation' structures are loosely (rather than strongly) coupled. Our forth basic set of elements is thus represented by both the opportunities and the limits of modularity (Ernst 2005).

As we said in the introduction, once built up on these four pillars, the model will be simulated and its results compared with other related evidences on the organization of industry.

A first comparison will be made with what we know from the massive literature on the relationship innovation vertical integration/disintegration. Starting from the seminal work by Robertson and Langlois (1995), the relationship between vertical scope and technological change has been extensively debated (Taymaz and Kilicaslan 2005).1 In general, vertical integration has been claimed to be preferable in front of system-like innovations - but only with a stable, or predictable demand - and in front of changes in the modules and subsystems of complex products. But when either technology or demand (or both) evolves rapidly, vertical integration might actually hamper the exploration of new solutions so that specialization and vertical disintegration become preferable. And this is more the case, the more modular the products of the firms are (Langlois 1992). Related to this, is the role played by the firm's distance from the technological frontier in its decisions of vertical integration (Acemoglu, Aghion, and Zilibotti 2002). In particular, it has been argued that, by mitigating the managerial overload of production and innovation activities, vertical disintegration might actually favor innovation, but just for firms in a neighborhood of the frontier, where innovation were higher. Conversely, when firms

\footnotetext{
${ }^{1}$ Summing up, Robertson and Langlois (1995) claim that "strategic" innovations — involving a drastic rearranging of capabilities, but within known boundaries — would favor vertically integrated firms over disintegrated ones. Conversely, a "parametric change" — occurring in certain known variables within a known framework — and a "structural change" — where variables and framework are both unknown - would rather favor market related mechanisms.

${ }^{1}$ Although modularity is taken into account in the model and in the simulation, we have kept it constant in this paper. For a deeper analysis of the role of changing degrees of modularity, see (Ciarli, Leoncini, Montresor, and Valente 2006)
} 
locate far from the technology frontier, imitation activities are more important, and vertical integration is preferred.

The second set of results we will consider the role of the evolution of the industry organization along its life-cycle. Also this issue has been massively investigated, and from both standard (i.e. contractual) (Aghion, Bloom, Blundell, Griffith, and Howitt 2005) and non-standard (i.e. competence based) perspectives (Utterback and Abernathy 1975, Abernathy and Utterback 1978). It has been argued, for example, that different stages impact differently on vertical integration as it can be necessary or not in overcoming the slack of market mechanisms for innovative products and components (Foss 1993). For example, in the introductory stage, new complex products might require an array of components substantially different from those developed by the incumbent firms, so that final producers might find convenient to integrate upward their suppliers to reduce 'dynamic transaction costs' (Langlois 1992). But when a maturation stage is reached, the increase in the demand for the newly introduced components, along with the entry of further intermediate suppliers, makes the development of each component relatively more autonomous, thus rendering vertical disintegration more convenient as it reduces production costs through specialization. This holds more true in the declining stage, when technological change slows down and makes the interfaces among the product's components quite stable, while the relative competences diffuse both upward and downward. What occurred in the computer industry is an illuminating example of this kind of cyclical pattern (Bresnahan and Malerba 1999).2

\section{The model}

This section describes how we model the interaction between a technological landscape and market organization. The model rationale, its main hypotheses and the behavioural assumption are first discussed (Section 3.1) in the light of the theoretical background discussed above (Section 2), to which Section 3.2 will provide a formal description.

\subsection{Rationale and hypotheses}

We consider a market for a product, composed by several modules, whose quality and price depends on the quality and production/purchase costs of the modules. Therefore, producers' activities are oriented to improve quality and costs for modules, under the constraints posed by available technological and economic possibilities.

We assume that the overall strategy applied by the firms consists in continuous random exploration of some of the possibilities of change of their current

\footnotetext{
${ }^{2}$ A similar account can be given by focusing on the dynamics of the 'technological dialogue' which occurs between supplier and customer of a certain innovation, in order to specify the attributes of the new products and services to be introduced (Christensen, Verlinden, and Westerman 2002). Indeed, depending on this dialogue being 'structured' or 'unstructured' that is, occurring or not across interfaces which are specifiable, measurable and predictable it is, respectively, it can be convenient or not to move such interfaces from within to outside the firm. This is so because in the latter case, that is in the presence of an unstructured technological dialogue, the necessary information for the efficient functioning of the market, both from the supplier and the customer point of view, is actually missing.
} 
activities, and taking what appears an improvement in respect of the current condition. In other terms, we represent firms as observing a narrow local neighbourhood of their current condition and applying a myopic perspective, lacking the possibility to make an exhaustive assessment of the whole space of possibilities and evaluating all potential future outcome. This assumption, supported by the evolutionary literature cited above, is particularly justified in our analysis. Firstly, the firms' environment is highly complex, due to the strategic effects caused by the presence of competitors with similar conditions, and to the complexity of the technological landscape. Therefore, since facing a complex problem, firms can safely be assumed to be aware that, even assuming a desired optimal point may be identified, small errors in determining the starting direction to optimality can lead to huge errors of the arrival point. Secondly, our firms live in a competitive environment; therefore they need not only to identify highly rewarding conditions (technological and economical), but they also need to survive the path leading to those conditions. In other terms, even if an optimal point could be identified, there may be no economically viable path leading to it due to the lack of resources necessary to finance the losses incurred during the time of adjustment from the currently held condition to the arrival point.

The model deals with a population of firms with heterogeneous technological endowment that seek to innovate their product in order to satisfy demand preferences. All firms pertain to the same sector and produce one single, non homogeneous, product. The model draws on the Schumpeterian ideas that, firstly, technological change is, to a certain extent, ubiquitous and continuous, rather than isolated and extraordinary; secondly, that technological innovation concerns also product innovation rather than process innovation. Competitiveness is pursued, in our model, by three, related, means. Technological improvements allows to provide higher quality products, increasing the appealing of a firm's offer in respect of competitors. Production costs' savings, affected by economies of scale and costs' reducing learning-by-doing, and transaction costs 3 Decisions to outsource/integrate a module of the product, influencing both technological qualities and costs. Below we describe the principles guiding the implementation of these activities in our model.

\subsubsection{Technological landscape and innovation}

Firms have three ways to modify their product, i.e. to innovate: by developing a new technology for one of the components; by outsourcing one of the components to an external supplier; and by internalizing a currently externally sourced component. In any case, firms take the decision of adopting the innovation or rejecting it (maintaining the previous condition), depending on the technological performance provided by the product, which is determined by an evaluation of the technological state of the product in a technological landscape.

Concerning the technological landscape, we assume that exists a dynamics (that, for analysis purposes is assumed exogenous) determining the overall performance level of a given technological state. The performance is determined by the complex interaction among all the technological states of the modules composing a product. At any moment in time exists a technology (i.e. a state

\footnotetext{
${ }^{3}$ We ignore agency costs, which amounts to assume that agency costs affect equally all firms and the transaction costs refer to their net effect discounting the agency costs.
} 
for each module) which is the state of the art, providing the highest possible performance. However, the path leading to this optimal technology, that we called technological frontier, may be quite rough. In fact, firms cannot observe the individual technologies (one for each module) and those composing the frontier, but only the overall performances of different combinations of modules' states. A firm testing an innovation of a product far from the frontier may observe a fall in performance even if the innovation gets a module closer to the frontier ${ }^{4}$. Furthermore, the frontier itself moves continuously, so that the performance of a product cannot but fall continuously, unless innovation moves continuously the firm's technology toward the shifting frontier, generating a sort of competencedestroying technological change (Tushman and Anderson 1986).

In line with much of the literature (see, e.g., Nelson and Winter 1982) we assume that technological innovation is "local" and off-line. That is, an innovation is tested by testing a small change in respect of a known technology, since we assume as impractical the development of a technology radically different from the currently used one. A tentative innovation is assigned its (technological) performance value, which depends (in a highly non-linear way) on the distance of the tested technology from the frontier. An innovation is accepted if the performance of the new technology is higher than the alternative, currently adopted one.

\subsubsection{Costs}

The competitiveness of a firm depends on its product's technological quality and on its price. Prices are determined on a costs-plus bases, with a mark-up equal for all the firms. Costs are computed independently for each module of the product, and depend on three factors: economies of scale; learning-by-doing; transaction costs.

Firstly, the unit costs of producing small quantities of a given module are higher then those for producing large numbers of the same module. This effect, as we will see, is crucial in determining the advantage of suppliers. Secondly, a learning-by-doing effect decreases through time, other things being equal, the cost of producing a module with a given technological state. As an innovation is introduced on the module, the lower costs associated to the old technology disappears, restarting a new path of learning. This effect rewards, in a sense, the lack of innovation since it is assumed that "frozen" technologies allow for improvements on their production methods. Lastly, we assume the existence of transaction costs, making more costly modules acquired externally in respect of, other things being equal, the internal production. This assumption makes possible the externalization of modules only if: the supplier enjoys such a large production scale to off-set the transaction costs; or/and the suppliers' qualities is much better than that accessible by its clients.

\subsubsection{Outsourcing and integration}

As we have seen, we represent firms as eager adopters of new technologies, as soon they arrive within reach, and subject to almost "physical" laws determin-

\footnotetext{
${ }^{4}$ This is the typical property of local searches in complex landscapes (Kauffman, Lobo, and Macready 2000), that we generate by means of a more efficient and flexible model adapt to deal with real-valued variables rather than binary ones (Valente 2006)
} 
ing the levels of costs. Concerning organization decisions, instead, we assume that firms are very conservative, unwilling to introduce a change unless this is robustly certified as providing an advantage. This is because we assume that any change in the production system of a firm requires diffused and relevant costs of adjustment that, though being one-off, need to be justified only when the advantage is clearly assessed.

In practice we consider that a change in the production structure is accepted when several, independent tests at different times consistently indicate that the modification would increase the competitiveness of the firm. Firms consider modification of their production structure one module per time. A test consists in comparing the current competitiveness (i.e. the module internally produced or externalized) with that generated under the hypothesis of a different, best opposite production arrangement (externalized or internalized).

If the module under test is currently produced internally, the firms firstly selects all potential suppliers (i.e. firms producing that module) compatible ${ }^{5}$ with its current technology. Among these, the one providing the best performance is selected, and the resulting, hypothetical, competitiveness is compared to the current one. If the module is, instead, already acquired from an external supplier, the firm searches for better supplier (among those with a compatible technology) and also tests for the competitiveness of re-internalizing the module. In fact, even when firms have outsourced part of their production modules, they keep on experimenting technologies on the outsourced segments of production. It is therefore possible for a firm to discover a new technology for an outsourced module, so that to fill the technological gap with the supplier.

The next paragraph describes formally the most relevant routines used to implement the dynamics described above. In the following section we describe the configurations of the model implemented and the relative results.

\subsection{A formal description}

The model represents an artificial economic system in which firms compete in a consumers market by means of both internal innovation and organisational change. Both innovation and organisational changes are influenced by the (non) modularity that characterises the production of the consumers good. In particular, the interdependencies between the good's components turn the technological search into a complex task, and the organisational structure into a strategic configuration influenced by both cost and technological (knowledge) features.

The economic system that we represent is populated by $x_{f}(f=1, \cdots, N)$ 'follower' firms. Each firm produces an heterogeneous final good, by assembling $M_{j}(j=1, \cdots, \breve{M})$ components (input modules). The final good is defined over a set of $y_{i}(i=1, \cdots, I)$ 'quality' characteristics, which represent the same features across firms. Characteristics of the final good should be thought as the implicit use-value for consumers, in a Lancasterian way (Lancaster 1966). Therefore, characteristics with the same features across firms defines the good (and firms) as pertaining to a single sector. Eventually, we represent the final product as

\footnotetext{
${ }^{5}$ The test of compatibility consists in determining whether the potential supplier's technology is similar enough to the firms' own technology on that module. The reason is the same for not permitting firms to "discover" technologies far away from their current ones: too large "jumps" in the technological space disrupt the capacity of the firm to adjust to a radically new technology.
} 
a vector of characteristics $\bar{y}_{f}$, evaluated according to demand preferences. All firms need to use all $\breve{M}$ components, decide to produce some of them in-house $\left(M^{\iota}\right)$, and buy the remaining ones from suppliers in the market $\left(M^{\varepsilon}\right)$ - where $M^{\iota}+M^{\varepsilon}=\breve{M}$.

The way in which each component contributes to the final value of the good (measured through the characteristics' level) is thoroughly explained in our companion paper (Ciarli, Leoncini, Montresor, and Valente 2006), to which we address the reader interested in a higher level of details. For a more detailed account of the way in which the complex research in non modular environments is modelled via an emulation of the NK frameworks, through a PNK model, see (Valente 2006).

In each period $t$, each firm undergoes the following main steps:

1. on the basis of the market structure, resulting from firms decisions at time $t-1$ and from their technological achievements, the demand is computed allocating the relevant quantity to each firm;

2. firms then perform technological search, attempting to improve their product fitness;

3. with the same aim firms reconsider the organisation of production;

4. finally, the value of their production is updated for the following period $t+1$.

In what follows we first describe the model variables, and then the dynamics of technological and organisational change.

\subsubsection{Real variables}

Given the relevance of final good's characteristics (which are the objective of the firms), the model is demand driven. Demand changes monotonically as a function of good's characteristics and price. Consumers define a target demand

$$
D^{*}=H+\frac{1}{\bar{p}^{\epsilon_{p}}} \prod_{i=1}^{I} \bar{y}_{i, t-1}^{\epsilon_{c}}
$$

and firms adapt smoothly (due to information sluggishness)

$$
D_{t}=\sigma^{d} D_{t-1}+\left(1-\sigma^{d}\right) D_{t}^{*}
$$

where $H$ is a constant; $\epsilon_{p}$ and $\epsilon_{c}$ the aggregate preferences for, respectively, price and quality characteristics; $\sigma^{d}$ determines demand path dependency (information lags); $\bar{p}=\sum_{f=1}^{N} p_{f} \cdot m s_{f}$ and $\bar{y}_{i, t-1}=\sum_{f=1}^{N} y_{f, t-1} \cdot m s_{f} .6$

Market shares, $m s_{f}$, are determined as the relation between firms' own competitiveness $\chi_{f}$, and the overall level of competitiveness. As for the demand, we take into account that firms need to adapt their production capacity to demand changes. We firstly compute the theoretical market share, $m s_{f}^{*}=\frac{\chi_{f, t-1}}{\sum_{f} \chi_{f, t-1}}$, to

\footnotetext{
${ }^{6}$ Product's characteristics values are computed in the second and third fraction of period $t$ (see below), after innovation, and will determine the demand in the following period. Consumers refer to the actual price and characteristics, which indeed depends on the market structure in the previous period $t-1$.
} 
which the real one adapts through time: $m s_{f, t}=\sigma^{m} m s_{f, t-1}+\left(1-\sigma^{m}\right) m s_{f, t}^{*}$ (where $1-\sigma^{m}$ is the speed of adaptation of firms' production capability).

We define competitiveness as the capability to adapt to demand features with respect to price levels and characteristics' values, $\chi_{f, t-1}=\frac{1}{p_{f}^{\epsilon_{p}}} \prod_{i=1}^{I} y_{f, i, t-1}^{\epsilon_{c}}$. We use values of period $t-1$ to determine competitiveness in time $t$, as the innovation of product components occurs at the end of the period, when firms have already undergone production (any innovation results appear in the market only after their actual completion, while production follows its daily routine).

Changes in the values of characteristics are discussed in the following section 3.2 .2 ,

Firm specific prices for the consumers good are affected also by the organisational choices taken in the preceding periods. Final prices, in fact, vary according to the cost of components (bought in the supplier market or manufactured internally) $p$, the cost of labour $w$, the level of labour productivity $A$, and the mark-up added to variable $\operatorname{costs} \nu$ :

$$
p_{f}=\left(1+\nu_{f}\right)\left[\frac{w_{f}}{A_{f}}+\sum_{j=1}^{\breve{M}} \underline{p}_{f, j}\right]
$$

The price of intermediate goods (components) differs between those produced within the firm $\left(M^{\iota}\right)$ and those outsourced $\left(M^{\varepsilon}\right)$. First, input suppliers add a mark-up to their production, increasing the price of outsourced components (which covers part of the transaction costs). Second, we take into account learning dynamics and economies of scale, that may yield cost advantages when specialising in the production of specific inputs, supplied to other firms (more below on the way in which components price affect the decision to outsource/internalise parts of the production). Hence, when bought in the market, the input cost reflects the strategy of the supplying firm $x_{g}$. Otherwise, the cost depends on how long the firm has been using the input technology for (learning), and on the quantity produced of that component (scale). In fact, the period following an innovation on a component (or its internalisation), its cost is set at the initial level $b_{f, j}$. Otherwise, through time the learning process sets in, and the cost converges to a target price $\underline{p}_{j}^{*}$, which itself reduces with the increase in the production scale.

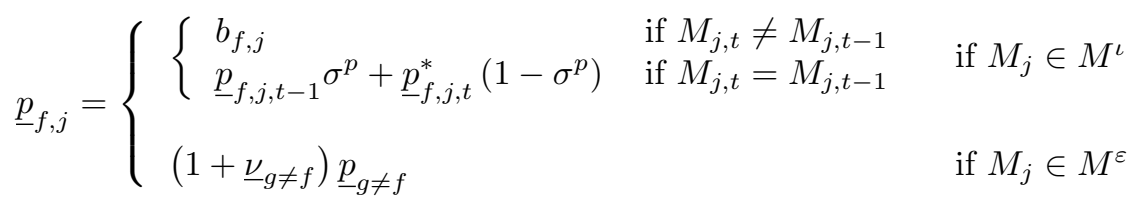

where

$$
\underline{p}_{f, j, t}^{*}=\frac{b_{f, j}}{1+\theta \underline{D}_{f, j, t-1}} ;
$$

is the target price of firm $x_{f}$ for the $M_{j}$ component produced internally; $1-\sigma^{p}$ the learning factor (the speed at which the firm achieves to exploit economies of scale); $b$ is a constant; $\theta$ a parameter that accounts for the scale factor; and $\underline{D}_{f, t-1}$ is the demand faced by the single module in the previous period. 
Given the aggregate demand (Equation 2) firms then undergo their own production $Y_{f}=D \cdot m s_{f}$. They produce using a fixed coefficient production function, with no financial constraints, and they command the relevant quantity of inputs, either to an internalised department (if $M_{j} \in M^{\iota}$ ) or to an external supplier (if $M_{j} \in M^{\varepsilon}$ ). Being our main focus in this work the relation between intermediate components features, product technological architecture and market organisation, we simplify the production side assuming that input coefficients are all equal to one. The effect of the different components is reflected in their contribution to the quality characteristics of the final good (see following section 3.2.2). Allowing for these assumptions, the current demand for each single component $j$ of firm $x_{f}$ closes the production side; total intermediate demand thus sums up in-house production and the component sales to clients, $\psi_{f, j, t}=\sum_{g \neq f \in \mathcal{C}_{t-1}} Y_{g, t}$ as follows:

$$
\underline{D}_{f, j, t}=Y_{f, t}+\psi_{f, j, t}
$$

where $g$ is any buyer firm pertaining in time $t-1$ to the set of clients $\mathcal{C}$ of firm $x_{f}$. It goes without saying that when a module is outsourced, its production is nil.

\subsubsection{Internal product innovation}

Once concluded the market transactions (defined in period $t-1$ ) firms undergo internal innovation in order to increase their competitiveness $(\chi)$ in the market, by improving the quality characteristics of their final good. ${ }^{7}$

Internal innovation mimics the exploration dynamics on a complex technological landscape using a slightly modified version of the PNK model described in Valente (2006). In sum, 8 in each period firms attempt to twist the value $\xi_{j}$ of one randomly drawn product module $M_{j}$, and evaluate the result on the product fitness (which, we recall, reflects market preferences) defined as:

$$
\phi_{f}=\prod_{i=1}^{I} y_{f, i}^{\epsilon_{c}}
$$

In fact, the value of each module $m_{j}$ contributes linearly to the final value of each characteristic:

$$
y_{i}=\sum_{j=1}^{\breve{M}} \alpha_{i, j} m_{i, j}
$$

(where $\alpha_{i, j}$ is the contribution of module $j$ to characteristic $i$ );

and it reaches its maximum level when the position of its element $\xi_{j}$ on the multidimensional technological landscape is complementary to the other interdependent $\xi_{l \neq j} 9$

\footnotetext{
${ }^{7}$ Note that, once completed the production process, both product innovation — that affects competitiveness through technological factors - and organisational changes — that affect competitiveness through both technological and cost factors - will affect market transactions only from the following period $t+1$.

${ }^{8}$ An exhaustive discussion on the model's properties, found in Valente (2006) for its original version and in Ciarli, Leoncini, Montresor, and Valente (2006) for a similar modified version applied to a market, is skipped in this venue.

${ }^{9}$ The number of dimensions, and the intrinsic complexity of research, is given by $\breve{M}$.
} 


$$
m_{j}=\exp \left(\kappa\left(\xi_{j}-\mu_{j}\right)^{2}\right)
$$

given the technological architecture of the good $\left(a_{j, l}\right)$

$$
\mu_{j}=\sum_{l \in \aleph_{j}} a_{j, l} \xi_{l}+c_{j}
$$

$\mu_{j}$ thus accounts for the level of (non) modularity of the product, the technological interdependence between modules; where $a_{j, l}=[-1,1]$ is the effect of the position of $\xi_{l}$ on the value of $m_{j} ; \kappa$ is a constant that allows to change the support of the Gaussian function; $\aleph_{j}$ is the set of the $l=1, \cdots, M \neq j$ modules interdependent with $m_{j}: 10$ and $c_{j}$ should be interpreted as the technological frontier that firms attempt to approach:

$$
c_{j, t}=\bar{\mu}_{t}-\sum_{l \in \aleph} a_{j, l} \bar{\mu}_{t}
$$

where

$$
\bar{\mu}_{t}= \begin{cases}\bar{\mu}_{t-1}+\zeta & \text { with probability } Z \\ \bar{\mu}_{t-1} & \text { with probability } 1-Z\end{cases}
$$

follows a non negative linear increase with small variations $\zeta=v \cdot \omega$, where $\omega$ is a parameter tuned to test the effect of different increasing magnitudes of technological change (shift in the technological frontier); $Z$ is a parameter tuned to consider the effect of the pace of technological change (periodical changes in the frontier); and $v \sim U[0,1] .11$

Note that the technological frontier does not define a ceiling, but rather the fitness of the cardinal position $\xi_{j}$ of each component. Indeed, the continuous (exogenous) change of the technological landscape requires firms to adapt their past technological configuration, in order to catch up with competition. This may have effects on the organisational structure, such as when firms outsource too many units of production and loose control on the relation between product architecture and technological change.

As mentioned, firms may produce both for the final and the intermediate market. Firms enter the market fully integrated, producing the final product and every component. In the baseline model we make the strong assumption that components suppliers cannot innovate on single modules sold in the intermediate market — i.e. they become fully dedicated to production. 12 Eventually, the innovation routine describes as follows:

\footnotetext{
${ }^{10}$ Note that when $\aleph_{j}$ is an empty set the technological problem faced by firms is very simple, like the case in which $K=0$ in NK models. As we show in Ciarli, Leoncini, Montresor, and Valente (2006), it is straightforward to demonstrate that the higher the $a_{j, l}$, the more difficult is the research on the technological landscape, and the more likely the event of technological lock-in. This is even more the case when $a_{j, k}<0$.

${ }^{11}$ In order to avoid results conditional on a unique type of technological change (linear increase), we have controlled also for a technological frontier that follows a random walk $(v \sim U[-1,1])$ obtaining very similar results. Nonetheless, note that the difference between a linear and a stochastic technological frontier can be interpreted as, respectively, the socalled competence--destroying and competence-enhancing technological change (Tushman and Anderson 1986)

${ }^{12}$ Instead, producers using a component only internally can change its technological properties. Nonetheless, we will show how results differ when this assumption is relaxed.
} 
1. each firm $x_{f}$ randomly draws one module $\tilde{M}_{f, j}$ with equal probability $1 / \breve{M}$ (i.e. independently on whether they are outsourced, sold, or produced only for internal use);

2. if $\tilde{M}_{f, j}$ is sold in the intermediate market $\left(\psi_{f, j_{\tilde{M}}}>0\right)$, besides being used for its own product, the innovation step is skipped.

3. in any other case the firm attempts to improve its technology following a random search strategy, 13 through the following three steps:

(a) explore: changes the position in $\tilde{M}_{f, j}$ on the technological landscape through a local search, by randomly drawing a new $\xi_{f, j}^{*} \sim$ $U\left[\xi_{f, j}-\delta, \xi_{f, j}+\delta\right]: 14$

(b) test: compares the initial fitness of the good $\phi_{f}$, with the fitness attained after the technological change, $\phi_{f}^{*}$;

(c) innovate: accepts the technological change if the new configuration yields a higher fitness $\left(\phi_{f}^{*}>\phi_{f}\right)$ and $\xi_{f, j}$ moves to $\xi_{f, j}^{*}$.

We stress once more that, due to the way in which the technological landscape is represented, a change in the position of one module on the landscapes affects the performance of the remaining modules $\left(\mu_{l}\right)$ - depending on the architectural structure (given by the $a_{j, l}$ ) — but not their position $\xi_{l}$. Hence, a technological change in period $t$ influences the following innovation path 15 Note also that up to now we have been considering only the technological fitness, in terms of quality characteristics, as the price is not influenced by product innovation.

Three more aspects are particularly relevant, as they influence also the decision of internalising/outsourcing bits of the production chain. First, we are assuming that firms undergo innovation also when they do not manufacture the component directly. Therefore, repeated successful changes on an outsourced module may induce the firm to internalise it in the future, as it has attained a higher/better suited technological performance. Conversely, given that firms start with different technological configurations (random distribution of $\xi_{j}$ ), firm specific innovation patterns may attract producers that are willing to outsource part of their production. Finally, any change in a module (when successfully completed) restarts the learning process that allows to take advantage of scale/specialisation economies (Eq. 4). Given that costs have an important role in the decision of outsourcing the production, technological change may both reduce the probability of being selected as an intermediate supplier and increase the probability of outsourcing the module (if a really cheaper one is found). But it can also attract firms for which the new component becomes technologically attractive (outweighing the higher price with respect to competing suppliers). The final outcome depends on a wide number of interaction within the market, that can be shown only through simulation techniques.

In order to have a better grasp on the above considerations, we move to explain the organisational choice in the model.

\footnotetext{
${ }^{13}$ See Valente (2006) for a discussion on the differences between search strategies.

${ }^{14}$ Where $\delta$ represents the maximum achievable span of a single step technological change.

${ }^{15}$ More details on this relevant aspect in Ciarli, Leoncini, Montresor, and Valente (2006).
} 


\subsubsection{Organisational change}

No matter the result of the innovation process, in each period firms evaluate also their organisational structure. Each firm initially randomly draws one particular $\hat{M}_{f, j}$ with probability $1 / \breve{M}$. The subsequent process then differs depending on whether $\hat{M}_{f, j}$ is currently produced in-house or acquired in the market. Indeed, in both cases of integration and outsourcing we take into account that a change in the organisational structure requires a thorough consideration of the opportunities, and cannot take place simply because firm fitness benefit a one shot marginal increase. Thus, a firm decides to integrate (outsource) an external (internal) component only when a positive opportunity has occurred repeatedly (i.e. for a given number of periods, recursively).

We start from the outsourcing algorithm.

\section{Outsourcing}

In brief, each firm first checks whether it can find a supplier that produces a better input, at a similar technological level, and eventually outsources the production of the component. As mentioned above, the firm may find a specialised supplier that has reduced its costs exploiting economies of scale, or a component that fits better its product architecture. The outsourcing routine has the following dynamic:

1. exploration: the firm $x_{f}$ initially searches whether there are firms selling the component $\hat{M}_{f, j}$ on the intermediate market;

2. if there are, it selects the $x_{g \neq f}^{\prime}$ producers that have attained a similar technological position $\xi_{f, j_{\hat{M}}}$ for that module, such that $\left|\xi_{f, j_{\hat{M}}}-\xi_{g, j_{\hat{M}}}\right|<$ $\gamma ; i^{16}$

3. if no supplier is eligible, the outsourcing step is skipped;

4. else,

(a) test: the firm tests its competitiveness when using the outsourced input with the new technology $\xi_{g, j_{\hat{M}}}$ and cost $\underline{p}_{g, j}$ and compares the initial fitness $\phi_{f} / p_{f}^{\epsilon_{p}}$ with the new one $\phi_{f}^{*} / p_{f}^{* \epsilon_{p}}$;

(b) if the test is negative $\left(\phi_{f} / p_{f}^{\epsilon_{p}}<\phi_{f}^{*} / p_{f}^{* \epsilon_{p}}\right)$, no outsourcing occurs;

(c) else,

i. the firm considers how many outsourcing attempts $\varepsilon$ it has already performed in the past;

ii. after a given number of positive attempts (i.e. tests after which the firm would have outsourced) $(\varepsilon>\varpi)$, the firm decides to buy the component from the selected firm;

iii. else $(\varepsilon<\varpi)$, postpone the decision to a following period, keeping track of the positive test.

\footnotetext{
${ }^{16}$ We use for $\gamma$ the same value of $\delta$, which defines the innovation possibilities for a firm in one single step
} 


\section{Internalising}

If the selected module $\hat{M}_{f, j}$ is already outsourced, the firm first searches for a better supplier, and then considers the opportunity of integrating its production anyway. The search for a new supplier follows exactly the outsourcing routine described above, to which we address the reader. Though, as mentioned, the producer $x_{f}$ may have attained a high technological level on $\hat{M}_{f, j}$, as a consequence of a series of successful technological innovations. The internalisation routine then goes as follows:

1. test: the firm tests its competitiveness when producing the component in-house with respect to both the technological position achieved $\xi_{f, j_{\hat{M}}}$ and its cost $\underline{p}_{f}$ and compares the initial 'outsource' fitness $\phi_{f} / p_{f}^{\epsilon_{p}}$ with the new one $\phi_{f}^{*} / p_{f}^{* \epsilon_{p}}$;

2. if the test is negative $\left(\phi_{f} / p_{f}^{\epsilon_{p}}>\phi_{f}^{*} / p_{f}^{* \epsilon_{p}}\right)$, the firm keeps buying the module on the market (either the previous or the new supplier);

3. else,

(a) the firm considers how many attempts to internalise $\iota$ it has already undergone in the past;

(b) after a given number of positive attempts (i.e. tests after which the firm would have internalised) $(\iota>\varpi)$, it decides to integrate the component, exploiting its technological advance, and increasing the chances to follow the changes in the technological frontier;

(c) else, it postpones the decision to a following period, keeping track of the positive test.

The technological and organisational changes undergone in the second part of each time period $t$ define firms and market conditions at the beginning of the following period $t+1$.

In order to close the model, the following variables are updated: the value of quality characteristics $y_{f, i, t}$, which determine both the average market value $\bar{y}_{f, i, t}$ and firms competitiveness $\chi_{f, t}$; and the demand faced by each module $\underline{D}_{f, t-1}$.

\section{The results: technological change and the dy- namics of industrial organization}

The goal of the simulation is to discuss the effects of technological innovation on the dynamics of industrial organization. We believe that the relationship runs in both directions: also the economic events arising in an industry influence the levels and rate of changes of a technology. These two phenomena generate a complex feedback loop between technology and industrial organization. For obvious reasons of simplification of the analysis, however, we ignore the links from economic phenomena to the technological possibilities. This assumption allows a clear understanding of the other direction, since we can study how different (exogenous) technological dynamics influence industrial organization. 
For a similar reason, we also apply another, highly unrealistic but methodologically necessary, assumption: we prevent entry and exit of firms. This assumption permits to avoid that the results are influenced by demographic phenomena and, crucially, removes an extremely relevant and peculiar source of innovation: innovative new entrants. These lack, by definition, entrenched technological and production conditions, limiting the scope of choice. But face the problem of establishing themselves on the market, requiring relevant initial investment. Modelling new entrants would require a high number of largely arbitrary assumptions, potentially obscuring the phenomena generated by the dynamics of incumbents, and therefore we prefer, in this initial exploration of the model, leaving aside the problem of entry.

It is worth noting that these two simplifying assumptions concern heavily related aspects. In fact, we may expect that, for example, when incumbent cannot (or prefer not to) be close to the technological frontier new entrant will be more likely manage to squeeze into the market to exploit the technological possibilities not tapped by incumbents. Conversely, when incumbent are at, or near, the cutting edge of the technological possibilities new entrant will have little possibilities to enter a market with strong qualitative advantages. Therefore, the two (supposedly related) phenomena of determinants of the technological frontier and entry/exit are likely to affect the state of a market in different ways than those generated by the incumbents' activities. To study this latter phenomenon we therefore ignore the former, considering the setting described in the following. 17

We consider a market for an unspecified product, whose production process entails several phases, or, equivalently, is composed by a set of modules. We consider a number of firms, all of them engaged in offering this final product to the market of consumers, but being free to determine whether to produce internally all the modules, or purchase one or more of them from an external supplier (chosen always among the members of the industry). Starting from an arbitrary initial condition, we will discuss the events leading the industry's firms to strike their balance between the trade-off they continuously face regarding costs (e.g. internal production vs. outsource) and "quality", represented by the technologies of the modules used to assemble the final product.

Our major focus will be on the average number of modules produced internally by the firms. Generally speaking, higher level of integration allows, other things being equal, a relatively easier discovery of technological improvements, since firms can tailor the innovation on each of their module to the rest of their technologies. However, the existence of a large number of integrated firms prevents the exploitation of the economies of scale that may be arising from a few, large producers for each module. On the other hand, a disintegrated market, where much of the total production is produced by acquiring components, is likely to be cost effective, but also to limit the scope of innovation. In fact, suppliers selling their modules to a large number of (heterogeneous) users are likely

\footnotetext{
${ }^{17}$ Isolating phenomena on the basis of logical distinction, though not of empirical evidence, is a normal methodological step, after which it is expected the extension of the analysis by merging the different strands of research providing a unique, more realistic, representation. To this extent, it is worth to note that our representation and the model design adopted is easily compatible to the endogenization of the technological frontier dynamics and to consider entry and exit of firms. We obviously preferred to implement a manageable, but less realistic, partial model, rather than implementing a undecipherable (apparently) complete model.
} 
to suffer limitation in changing their offer without introducing incompatibilities in respect of a sizable portion of their customers. We expect this aggregate tension to be generated by the micro-behaviour representing firms' activities, and the solutions to the indications of the effects of movements of the technological frontier. In the following, we provide a more detailed description of the settings used.

\subsection{Model setup}

We represent a group of 50 firms competing on the same consumers market, and following technological change rather than inducing it. Firms differ only with respect to the initial position of each component on the landscape $\left(\xi_{f, i, j}\right)$, randomly drawn from a uniform distribution centred on the initial level of the technological frontier $(\bar{\mu}) .18$ Firms produce a two characteristics good $\left(y_{i}\right)$, using six components $\left(M_{j}\right)$, all interdependent $\left(\aleph_{j}=\{1, \cdots, 6 \neq j\}\right)$, with a medium level of non-modularity (average $\left|a_{i, j l \neq j}\right|=0.46$ ). This setting amounts to define a relatively "messy" technological landscape, at an intermediate level in between a smooth, Fuji-like landscape and a rough, multi-peaked one. In practice, most of the points of the landscape admit a path away from local peaks, though this path may be narrow and tortuous.

In the first period, at the beginning of the simulation runs $(t=0)$, firms are fully integrated, and supply an equal share of the market $\left(m s_{f}=1 / 50\right)$. This simplifying assumption allows to avoid that erratic initial conditions determine the final results. Innovation strategy is random and local $(\delta=\gamma=0.05)$, while firms have perfect information on suppliers and choose the best one. Organisational change (integration/externalization) is quite slow and firms require five consecutive positive responses to the same strategy before actually adopting it.

Firms respond to an exogenous demand with unitary elasticities for both price and quality preferences $\left(\epsilon^{p}=\epsilon_{i}^{c}=1, \forall i\right.$ respectively), and adapt slowly to both demand changes and production adjustments $\left(\sigma^{d}=\right.$ sigma $^{m}=0.9$ respectively).

Demand preferences (for characteristics) change implicitly as the technological frontier moves - think of a group of localised firms that follow the technological change induced by innovative competitors. The rate $(Z)$ and magnitude $(\omega)$ of change of the frontier are the crucial elements on which the following results are discussed. They allow to suggest some answers to the hypothesis reviewed in the second section, and to show how the incentives listed at the beginning of this same section affect market organisation. The technological frontier increases monotonically $(0<\nu<1) 19$ We analyse industrial organisation dynamics in four different technological environments (Table 1), each of which is understood as a particular phase of a product life-cycle.

\footnotetext{
${ }^{18} \mathrm{Se}$ also Table 3 for specific parameter values.

${ }^{19}$ Note that the hypothesis on the direction of change of the frontier may apply only to certain - probably the majority of - markets/sectors. A monotonic change implies that previous competencies/technologies that defined consumers goods become obsolete and never recover (no space for modern vintage). Nevertheless, we have checked results also for a random frontier $(-1<\nu<1)$, finding no relevant differences. Results, not included for space reasons, are available from the authors.
} 
Table 1. Typified technological environments: Patterns of the technological frontier and product life cycle

\begin{tabular}{|c|c|c|}
\hline Frequency & $\begin{array}{l}\text { Large innovations } \\
(\text { high } \omega(=0.1))\end{array}$ & $\begin{array}{l}\text { Small innovations } \\
(\text { low } \omega(=0.001))\end{array}$ \\
\hline $\begin{array}{l}\text { Frequent innovations } \\
(\text { high } Z(=0.5))\end{array}$ & $\begin{array}{l}\text { - High turmoil } \\
\text { - Standard research }\end{array}$ & $\begin{array}{l}\text { - Low turmoil } \\
\text { - Standard definition }\end{array}$ \\
\hline $\begin{array}{l}\text { Infrequent innovations } \\
(\text { low } Z(=0.01))\end{array}$ & $\begin{array}{l}\text { - Low stability } \\
\text { - End of standard }\end{array}$ & $\begin{array}{l}\text { - High stability } \\
\text { - Mature product }\end{array}$ \\
\hline
\end{tabular}

\subsection{Discussion}

We run four groups simulations, aimed studying the cases for frequent or infrequent movements of the technological frontier, and for small or large steps of the same dynamics. We start presenting results produced under the assumption that firms selling a module on the market for intermediate products are not able to innovate this module. Later, we will replicate the same simulations without this limiting assumption. In order to smooth away the effects of randomness, we will present (unless otherwise specified) average values over multiple simulations with the same specifications and different pseudo-random values.

\subsubsection{Non cumulative dynamics}

\section{Large and frequent technological change}

A technological environment in which the frontier undergoes both frequent and large changes can be associated to the stage in which firms compete for the definition of the technological standard for a new product, such as the computer industry in the early 1990. Under those settings we show that, starting from a condition of full integration, firms in the consumers market tend to remain highly concentrated, and outsource only a marginal part of the production (see Figure 1, top series).

Such behaviour is very similar across firms, suggesting that, starting from very similar conditions, there is only one winning organisational strategy. In fact, the cross firms variance of the number of internalised components, low since the beginning, reduces through time (Figure 2, bottom series). In Figure 8 in the Appendix we show that, on average, firms end up outsourcing at maximum two modules, and a large part recover to full integration.

Two explanations account for these results: although initially some of the firms have an incentive to outsource some of the module (presumably those generating a very poor quality), intermediate suppliers promptly remain locked in the learning process of technologies that become outdated in a very short time. As soon as suppliers fall too far behind the technological frontier (and clearly so does the buyer, for that component) in-house production results become competitive, since they can be ameliorated, in contrast to externalized components. Secondly, appealing only to a small portion of the producers, suppliers of intermediate products cannot ripe the costs' advantages deriving from economies of scale, which are therefore dwarfed by transaction costs. As a result, as soon 


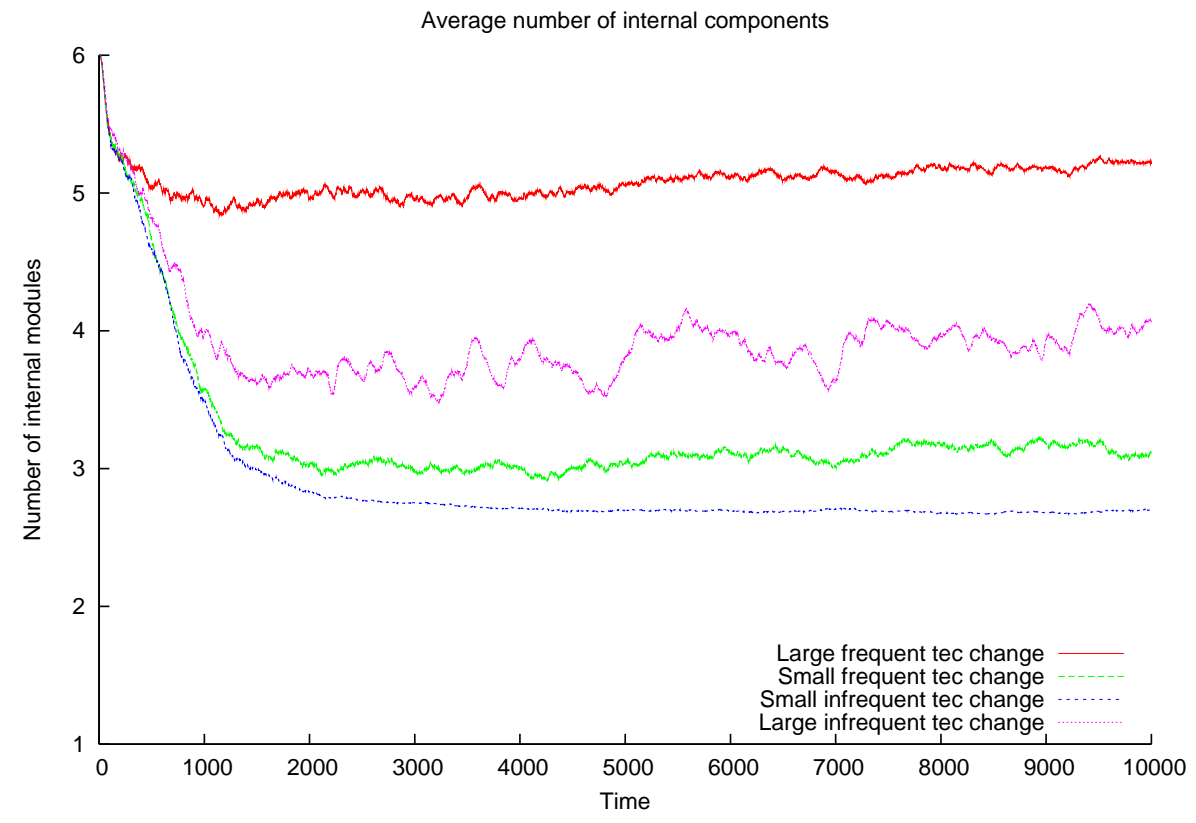

Figure 1: Evolution of the average number of integrated product components (modules): the four technological environments

as the qualitative advantage disappear, firms that initially externalize modules promptly re-internalize it.

Nevertheless, when firms catch up with the technological change, they have again an incentive to outsource a module, until the short-sighted strategy reveals non competitive. This cyclical behaviour of the industry can be appreciated in Figure 1.a in Appendix, where we show results from a single run, as opposed to the multi-runs average - which flattens away the single run cycles. The same shows for the cross-firms variance (Figure 10,a). Quite interestingly, organizational dynamic in this case also shows long waves of organisational changes.

The model also shows that, across simulations, firms outsource always the same components, while, for others, intermediate trade barely occurs, ${ }_{20}^{20}$ since almost all firms prefer to produce them internally. In other terms, our model differentiates modules that characterize each firm specific nature, from others that are generally traded off-the-shelf from global suppliers. Which module falls in which category is here less important than understanding how this can occur. As we already said, a module is externalized if there exists a potential supplier with similar technologies selling its product at a cheaper price. If, by chance, a producer can supply one of its module to many customers (because, by chance, it happens to be compatible with products from many producers), then economies of scale kick in and a large intermediate market for the module emerges. Customers of this market will then be able to concentrate their innovative efforts on the other modules, as required by the large and frequent movements of the technological frontier. The largely traded module cannot be advanced, becom-

\footnotetext{
${ }^{20}$ Results for which figures are not shown, for reasons of limited space, are available from the authors.
} 


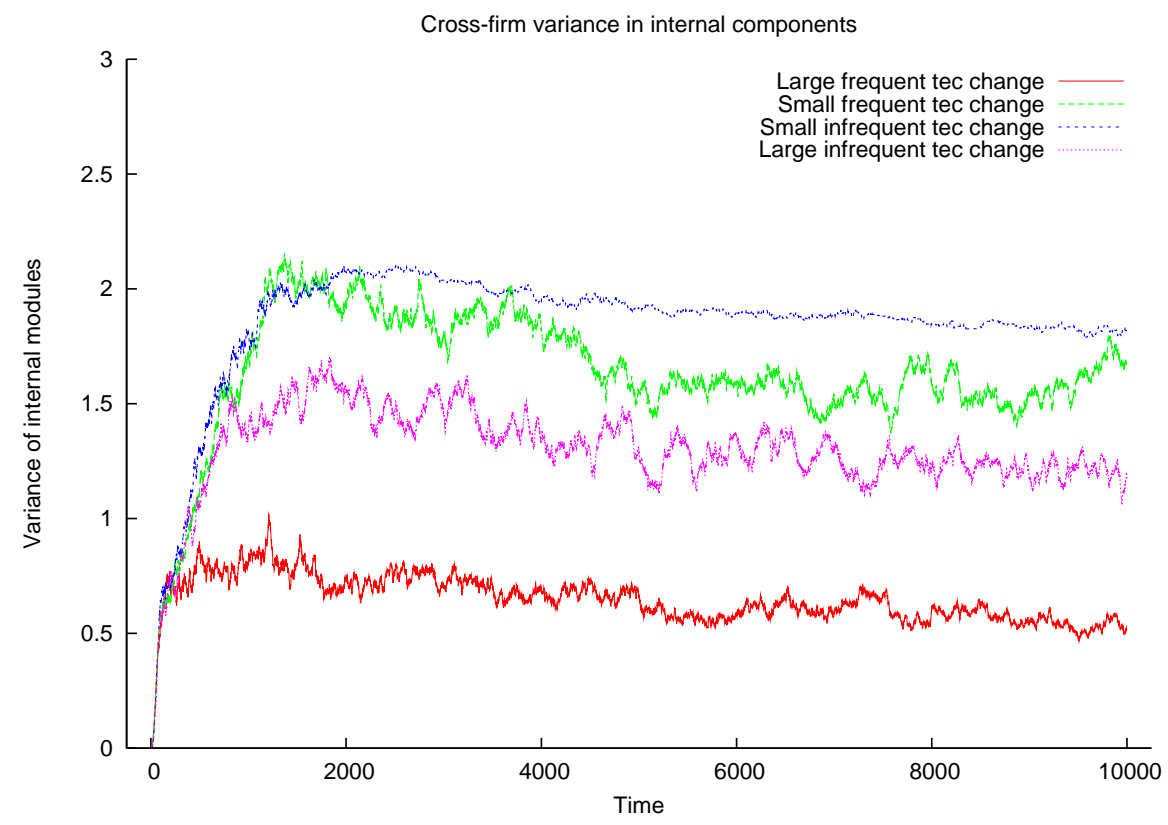

Figure 2: Evolution of the cross-firm variance in the number of integrated product components (modules): the four technological environments

ing, sooner or later, the bottleneck of further innovations. When this stage is reached, gradually the customers of this intermediate market starts to internalize the module in order to adapt it to the advancement introduced on the other modules. The first firm that manages to do the trick (advancing the technology of "laggard" module), becomes immediately attractive for the other customers of this already established market.

Given the high interdependency among modules, not all components can follow this pattern, because this would prevent any innovation at all. Therefore, only one or two modules can play this role, becoming, in a sense, the standard of the product, since all other components need to be adapted to this one. As any standard, its modification is rare, occurring only as very last resort after all other potential ways to improvements have been saturated.

As far as the market structure is concerned, shares in the consumers market are relatively concentrated (Figure 3, top series), provided that firms differ only with respect to the initial position on the technological landscape, and adopt the same random innovation strategy ${ }^{21}$ Results are better appreciated looking at the market shares evolution for a single simulation run (Figure 11.a in the Appendix). High concentration appears in the market shares of firms that manage, time by time, to catch-up with the frontier. The kind of technological change we are referring to creates in fact a continuous turmoil of temporary oligopolies. The firm that reaches the frontier obtains a sort of Schumpeterian monopolistic share, that is eroded and eventually wiped out as the competitive advantage shifts to other firms. Furthermore, the same kind of change determines a high

\footnotetext{
${ }^{21}$ The initial spike is due to the fact that some firms start with better technological conditions, and gain temporary oligopolistic positions.
} 
probability of failures in catching-up, which translates in the presence of a tier of numerous firms whose market share remains quite low. ${ }^{22}$

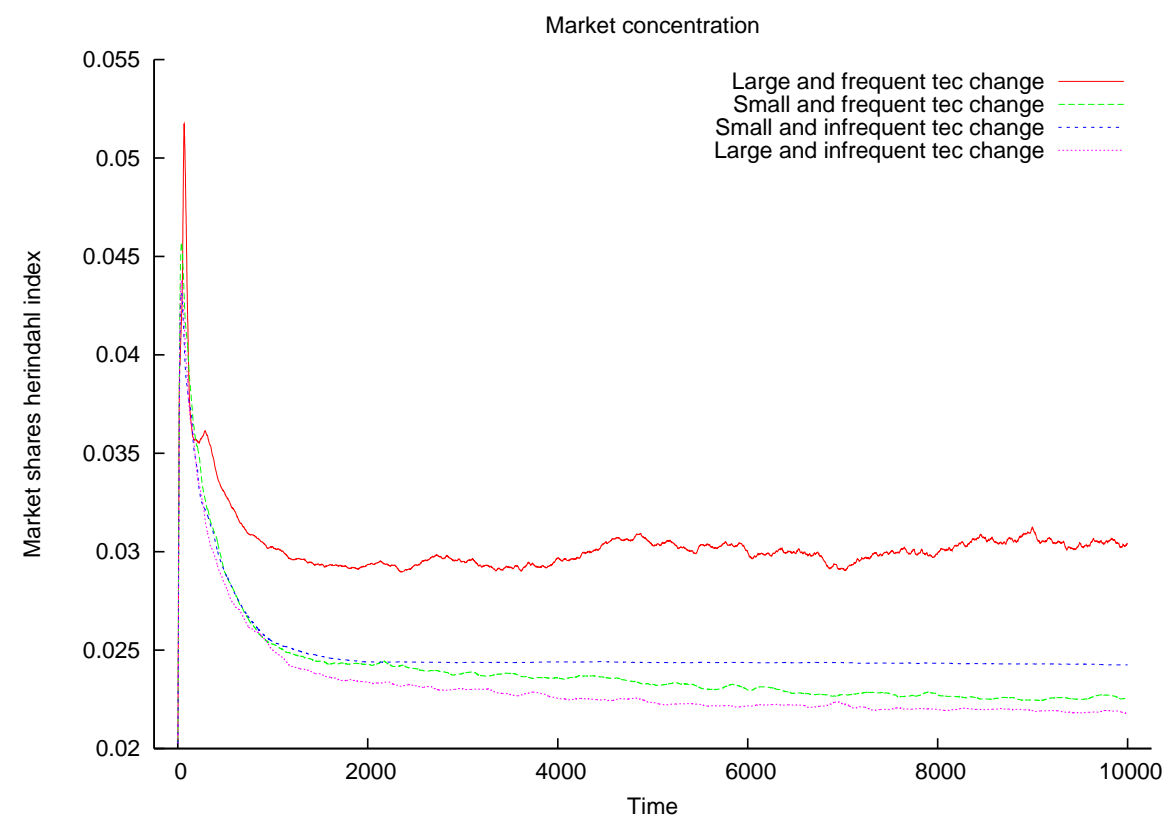

Figure 3: Evolution of market concentration in the consumers market (Herfindahl index): the four technological environments

\section{Large infrequent technological change}

The case in which relevant technological changes occur rarely can be associated to a stage that precedes the search for a product standard (bottom left of Tables 1). A disruptive transition between a long lasted mature product, and a completely different product that encompasses numerous innovations (think for example at the leap from typewriters to personal computers, through different generations of electric typewriters).

Although the technological frontier moves linearly, the industrial organisation cycles abruptly (Figure 1). These radical changes are better appreciated from a single run case (Figures 9.c and 10.c) where we show that the industry may steeply turn from a relatively de-verticalised condition (where firms, on average, outsource more than a half of the components) to a quite concentrated one (where firms, on average, produce five out of six components in-house).

The case of large but infrequent technological change in the frontier reinforces the above considerations on firms incentives to (dis)integrate. If technological change slows down in destroying the competencies of established firms in the consumers market, they have time in-between different shocks in which they can look for advantages of specialisation. On average, the organisation of

\footnotetext{
${ }^{22}$ Having ruled out entry and exit, the most these firms can do is to compete in a lower profile niche of the market, and from time to time they have the chance to pick-up a favourable modules' setting that allows them to catch-up again at very late stages.
} 
industry is now more disintegrated, but when the frontier places a large gap with firms' technology, they need to integrate to undergo modular R\&D. Nevertheless organisational strategies may differ between firms, as the higher variance (and its high oscillations) shows (Figures 2, second series from the bottom and 10.c). Although most firms end up with, on average, four components produced inhouse, some firms produce only three components, and others up to five (Figure 8, bottom left).

Also in this case firms choose specific components that are largely produced in-house, while only two of them (the less strategic ones for the product architecture) are almost always outsourced.

Quite interestingly, the market structure changes radically with respect to the previous case, and turns into middle-high competitive (Figure 3, first series from the bottom), i.e. very low concentrated. Focusing on a single simulation run (Figure 11.c), the turmoil in the market shares persists, but the lower frequency in technological change allows the sector to spread, from time to time, in a distributed number of market shares. In these time spans, competition turns from innovation-based to cost-based. Furthermore, the lower frequency of technological change makes the tier of firms unable to catch-up less numerous.

\section{Small frequent technological change}

When the technology changes frequently but with small steps, we can think of the stage in which a product standard has been eventually defined, and firms attempt marginal product improvements and process innovation (which are not addressed in this paper).

Under these conditions the vertical scope dynamics is now characterised by smoother cycles, and the incentive to take advantage of economies of specialisation are much greater. On average firms outsource half of their product components, and reintegrate them only occasionally (Figure 1). Even when considering a single simulation run (Figure 9,b), we obtain quite small oscillations in the number of internal components.

This is due to the fact that the continuous change in the technology occurs close to the exiting competences of firms, and cost advantages of specialised suppliers outweigh the loss from not being exactly on the frontier. The result is in line with the empirical evidence that shows that firms that maintain proximity to the technological frontier, tend to specialise on a limited number of components. Nevertheless, not all firms follow the same strategy, resulting in a high variance in the number of integrated components (Figure 2, third series from the bottom). Their number is almost uniformly distributed among firms, ranging from two to four (cross simulation average in Figure 8, top right).

The counter effect is that the average quality of the good on the market does not reach its maximum level. Notwithstanding, results show that a sector with a defined standard is characterised by a level of high competition (Figure 3, second series from the bottom) with continuous changes in firms' market shares (see market shares from a single run in Figure 11,b). Also in this case a low tier of firms with small market share emerges. But due to the low intensity of the technological change, this niche of weak competitors is relatively less numerous than the high tier of the market, which is instead distributed among a large number of firms. 


\section{Small infrequent technological change}

Finally, the case of a rare and small technological change is clearly that of a mature sector. When a sector is invested by small and low-frequency technological shocks specialisation and cost advantages become the relevant factors. Firms are always near to the technological frontier, and although modularity is low, once adapted the components technology to the product architecture, the main incentive for firms is to reduce production and transaction costs (technological transaction costs are almost nil). Therefore, the sector shows a very stable pattern of middle-high disintegration (Figures 1, bottom series and 9. d).

Nonetheless, this is the case in which firms may find the wider amount of options to sustain the competition. The variance of the internalised modules is the highest (Figure 2, top series), and firms may compete by producing in-house only one component or four of them (Figure 8 , bottom right).

The corresponding market structure is more concentrated, and reaches only a middle level of competition, inferior to that observed in the previous two cases (Figure 3). Non negligible degrees of oligopoly are now obtained by those firms which better manage to exploit the advantages of cost competition, but are able initially to find the 'right' pattern of innovative research (which then remains stable) (Figure 11,d).

\subsubsection{Innovative suppliers}

We explored the results of the model under a variety of conditions. We report here a few results providing some further possibility of comments. The same configuration producing the results above has been tested allowing suppliers of intermediate modules (those firms selling also intermediate components) to innovate these parts of the products. When intermediate firms can fully innovate on marketed components, technological change sums up to economies of specialisation. Therefore, there is very little trade-off between cost and technology strategies. Firms that innovate first, also start learning in advance and acquire economies of specialisation: they become attractive for firms that prefer to outsource their production, as they were less successful in innovating. ${ }^{23}$ Nonetheless, the trade-off between innovating - thus starting the learning process from scratch - and reducing production costs with the acquired technology through learning, is still at work. That is, if suppliers are able to innovate, and acquire economies of specialisation before the buyers have the time to end their contract, they cumulate successful outcomes. When this is the case, as expected, the level of disintegration is in general higher, regardless the technological environment (Figure 4).

This has to do also with the fact that the innovativeness of providers allows buyers a further alternative to catch-up with technological change. In fact, innovations sustained by suppliers do not substitute for internal R\&D. Firms, hence, now have an incentive to outsource most of the components, exploit competitors technological advance, and concentrate innovation on internal components. Indeed, this is the rational of 'true' outsourcing as compared to 'simple' subcontracting, which is a pure cost strategy. Note also that technological outsourcing is possible because firms produce a good with the same architecture. Eventu-

\footnotetext{
${ }^{23}$ Recall that here successful should be considered as an ex-post evaluation, as technological search follow a random strategy.
} 


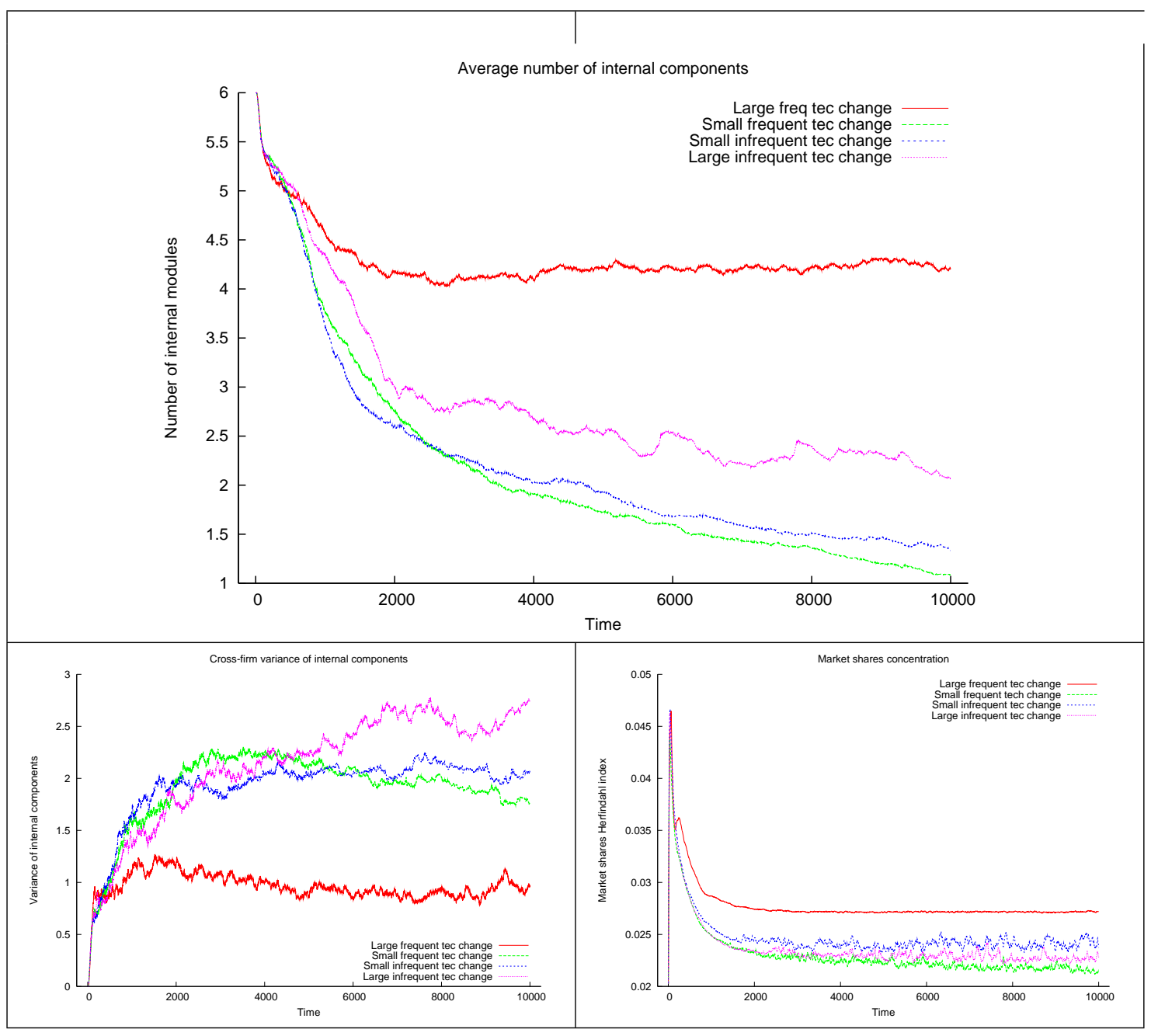

Figure 4: Evolution of the average number of integrated components (modules), the variance across firms, and market shares concentration: the four technological environments

ally, given the different initial conditions on the technological landscape, not all firms follow the same search strategy. Therefore, given the low level of modularity, very small mismatches in the technological advance of each component are critical for the overall fitness of the good. When the technological frontier experiences continuous and large movements, even if suppliers may innovate, firms need to keep an integral control of R\&D, as shown in Figure 4. With respect to the previous case of non innovative suppliers, the industry is thus more de-verticalised only to a small extent. The model also shows that in both cases (with and without innovative suppliers) the components that are seldom outsourced are the same ones; those most strategic in the product architecture. This consistency between outsourcing strategies disappears in the other tech- 
nological environments: in the case of innovative suppliers all components are equally outsourced ${ }^{24}$.

With innovating intermediate firms the model results show that the patterns of changes in the vertical scope are much smoother; the organisational cycles fade away, since once a supplier is identified, it takes time for the buyer to substitute for it. The only exception being with large and frequent changes in the technological frontier. Nonetheless, as Figure 4 shows the variance between firms organisational choice is quite larger.

When looking at market concentration, we find out that if intermediate suppliers innovate, the environment is less competitive in the case of large and frequent technological shocks. In fact, the risk of technological lock-in with an ever-changing frontier is high: firms that find since the beginning the 'right' pattern of the technological standard never have an incentive to outsource strategic components, as well as they may not be required (and bought) by competing buyers ${ }^{25}$ A closer look to the actual market shares shows that the market splits in two different tiers of firms since the very early periods: winners and losers. And no firm from the lower tier of the market is able to recover and catch-up. With respect to the other three technological environments, the level of market concentration is quite similar to the case in which suppliers do not innovate on marketed components. However, the concentration is characterised by increasing oscillations. With technologies smoothly changing, the market undergoes continuous turmoil.

\subsubsection{Summing up}

The industrial organisation that emerges in the different, typified, technological environments, implies a relation between the pace of technological change and firms organisational strategies. As already discussed in the literature, products with an integrated architecture induce firms to control the technological behavior of a number of its components. The extent of vertical integration then depends on how stable are technology and demand, regardless the cost of market transactions.

In Figure 5 we show the effect of the magnitude and frequency of technological change on the cross-firm average number of internal components, given the level of interactions between components. ${ }^{26}$ The corner extreme conditions show the outcomes discussed above, in the different technological environments that characterise different stages of a product life-cycle. Otherwise, the results from our model only partially confirm Robertson and Langlois (1995) hypothesis.

First, when technological changes are very predictable (either the magnitude or the frequency is sufficiently low), firm externalise most of the production. Second, as suggested by Robertson and Langlois (1995), firms tend to cut down their vertical composition when magnitude and/or frequency of technological change lay in a wide contour of their average values. The higher their value, the lower the vertical integration. Still, under those conditions of quite high technological instability, firms, on average, produce in-house approximately three

\footnotetext{
${ }^{24}$ Results available from the authors.

${ }^{25}$ Recall that firms may outsource a component only to firms that have attained a similar technological level on that component. Hence, firms that manage to create a technological gap with respect to competitors on a given product component, clearly do not have an incentive to outsource, and their component may not be acquired.

${ }^{26}$ Under the condition that suppliers may not innovate on marketed components.
} 


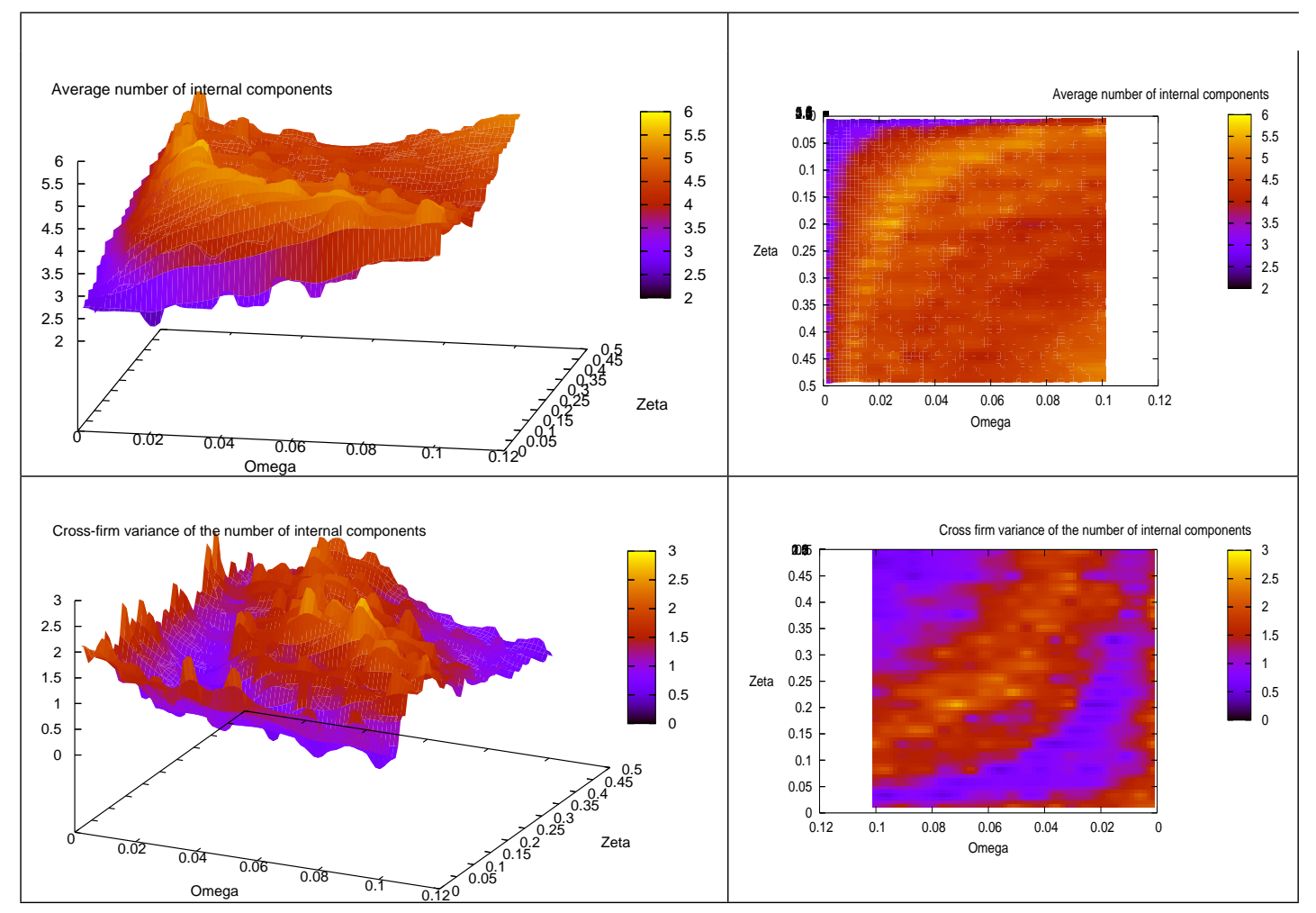

Figure 5: Technological change and firm organisation. Relation between the average number (and their cross-firms variance) of in-house components and magnitude ( $\omega)$ and frequency $(Z)$ of technological change

quarters of their components (between four and five out of six total components). Third, the extent of vertical integration, as shown above, increases again up to almost fully integrated firms when technological change magnitude and frequency reach their maximum level. Finally, quite interestingly, there is whole area of the parameters space, with either smooth and/or quite rare technological shocks, within which firms also reach their maximum level of vertical integration. This is due to the fact that, while too large jumps in the technological frontier leave most of the firms with outdated components (becoming complete followers, and dependent on the available components), in relatively stable - though continuously changing - technological environments, all firms keep up with the competition, and need the control over all components. In other words, technological advantages are still reachable, and pay off more than cost advantages.

Eventually, as shown in bottom rows of Figure 5, high vertical integration conditions are the most stable across firms. Conversely, in the large area of notso-high integration, with a relatively unstable technological environment, the variance across firms behaviour is quite high. With an average of four integrated components, some firms retain only two, while other are fully integrated. 
Those results suggest that the relation between modularity and vertical integration is somehow more complex. Once taken into account transaction costs, modularity is only one condition of the industrial organisation dynamics, even if a necessary one. When dealing with an integrated architecture good, our results confirm that the distance from the technological frontier is an important explanatory condition, which complements the modularity hypothesis.

Both conditions define the organisational behaviour of firms along the different phases of a product life cycle (Table 2). The phases are characterised by alternative technological conditions. Initially (bottom left) a completely new product (a prototype) is proposed on the market. We refer to this phase as a transitory one, occurring between the end of a mature product and the beginning of the race to define the new product standard.

Table 2. Typified technological environments: Patterns of the technological frontier and product life cycle

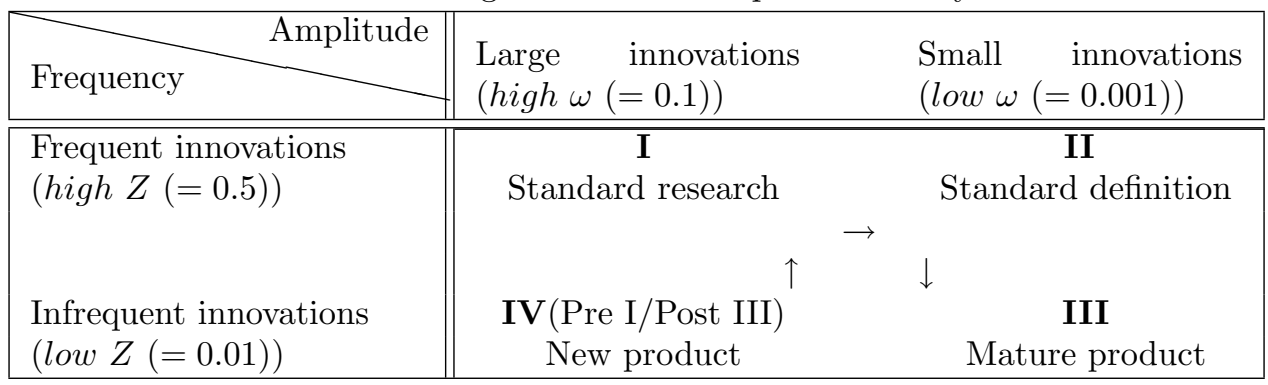

The following phase (top left) is then characterised by a continuous change in the technological definition of the product, mimicking the research for a product standard. Once a product emerges as a standard, firms shift to incremental innovations, continuously changing the definition of the product (top right). Finally, the product ends in the mature stage (bottom right) where technological changes induced by firms are rare and small. We take for granted that at this stage the product life cycle reaches an end; the next transition from the third stage to the first one implies the definition of a completely new good.

In Figure 6 we present results from a simulation where we exogenously modify the frequency and dimensions of shocks affecting the technological frontier. The four phases indicated in the graphs refer to the four values affecting the frontier in Table 2. This exercise shows how industrial dynamics (both as organisational change and market concentration) emerges in the different phases of a product life cycle.

If we consider the case of non innovative suppliers, firms start to integrate when new products are initially proposed on the market (Phase IV). The behaviour is highly cyclical - and quite different across firms (Figure 6, bottom left) - until firms start to compete to define a standard for a new product (Phase I), when the technology is continuously, and largely, updated. At the beginning of the standard definition, some firms are able to acquire higher market shares, which are suddenly eroded during the standard definition. Once the product technology has been defined, and only incremental (although frequent) changes occur, a smooth process of disintegration characterise the industry (Phase II). Though, the organisational strategy is now much more diverse 


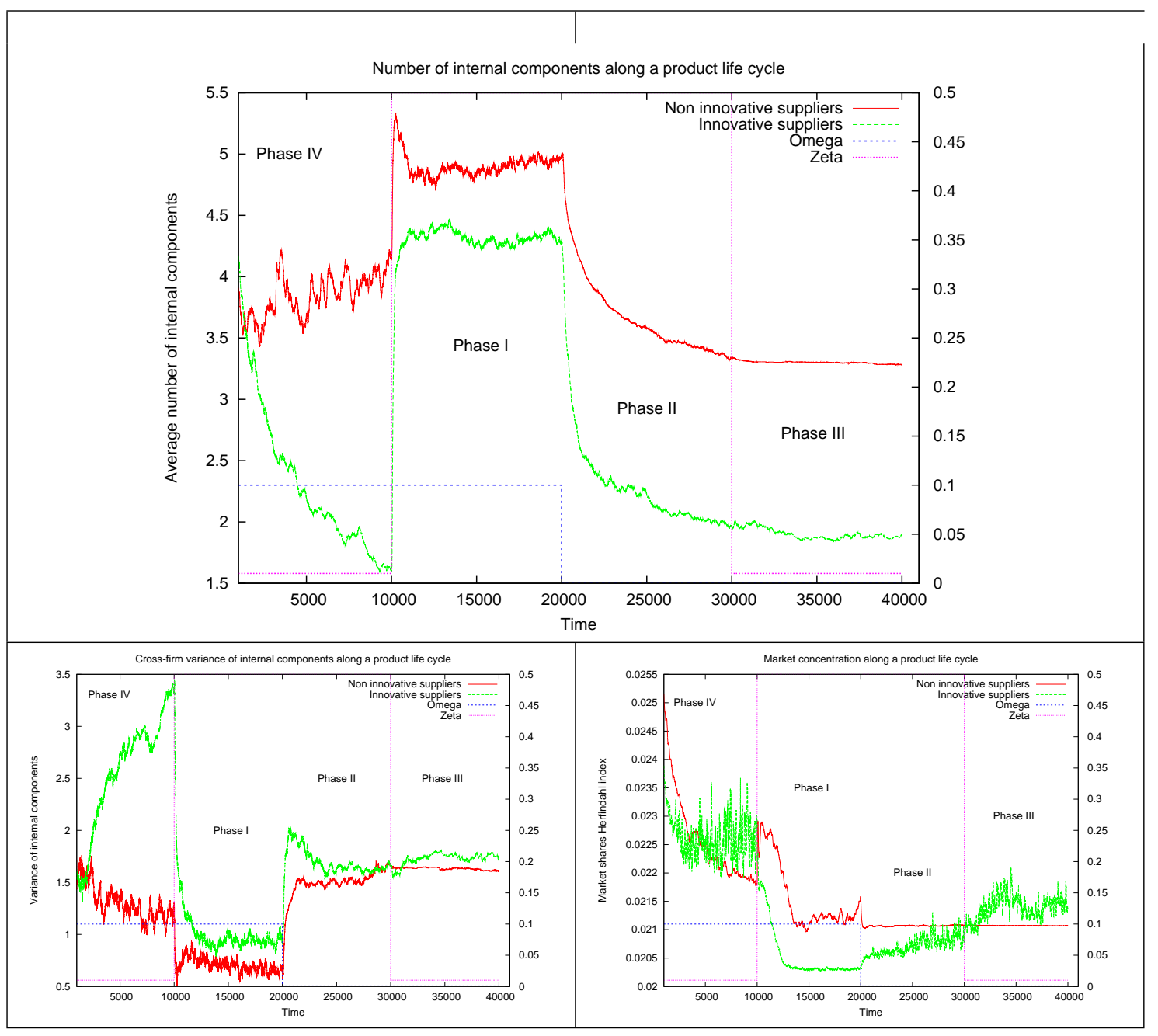

Figure 6: Evolution of the average number of integrated components (modules), the variance across firms, and market shares concentration: the four technological environments

among the competing firms. The industry definitely stabilises, with constant organisational structure, market concentration and cross-firms variation, during the maturity stage of the product, when innovation become rare and incremental.

Considering suppliers that innovate on the intermediate goods, during this last stage the market concentrate on firms that have innovate (and organised) more successfully. 


\section{Concluding remarks}

The paper has investigated how organization and structure of an industry evolve over time once the competitive behaviour of its firms is modelled by retaining some crucial elements of 'complexity', which do not usually enter in the standard analysis. First of all, firms follow search heuristic, rather than optimal behaviour, in making choices about their technological level and their organizational structure (namely, their vertical scope). Second, in these choices they are asked to solve a continuous trade-off between exploring something new in search of dynamic efficiency and exploiting something known in search of static efficiency. In order to retain these elements, we have built up and simulated an agent-based model. In it firms produce a complex good by using a modular technology in terms of components, and are continuously required to update their technological competences. By simulating this model, the paper is able to reproduce some stylised facts of industrial dynamics whose micro-foundation is usually quite qualitative and based on case-studies.

At the outset, we got confirmations that the specific stage of the life-cycle of a certain industry matters, affecting its dynamics as a result of the technological and organizational choices of the firms. In the introductory stage, a general pattern of high vertical integration emerges, as it represents the most convenient way to deal with the competition for a new standard. The industrial structure of the sector shows high levels of concentration, but the monopolistic power shifts continuously in a sort of Schumpeterian pattern of creative destruction. In the maturity stage, instead, when a standard is obtained, a disintegration pattern allows the exploitation of cost advantages rather than the upgrading of the current technological profile, which change more gradually. What is more, the market structure becomes quite competitive as cost competition is relatively less selective than the technological. These results are quite robust with respect to the innovative behaviour of intermediate suppliers.

Remarkable differences instead emerge relative to the role of the technological frontier. Still confirming the results of the literature on the topic, when technological discontinuities are quite consistent and leave incumbent firms far behind, vertically integration turns out the only viable solution to catch-up. But the pattern of vertical integration diminishes in the neighbourhood of the current technological competences.

The last part of the paper deals with the introduction of two elements in order to complete the picture. Indeed, with the presence of innovative suppliers, smoothers dynamics somehow emerge, as the trade-off between outsourcing and technological search looses importance, leaving more space for economies of specialisation. Finally, a life-cycle model can be depicted if the different phases are combined to mimic a sort of dynamic war for standards, which calls for high levels of organisational/technological change from the firms side. 


\section{References}

Abernathy, W., And J. Utterback (1978): "Patterns of industrial innovation," Technology Review, 80, 41-47.

Acemoglu, D., P. Aghion, and F. Zilibotti (2002): "Vertical integration and distance to frontier," Working paper, NBER No. 9191.

Aghion, P., N. Bloom, R. Blundell, R. Griffith, and P. Howitt (2005): "Competition and innovation: an inverted-u relationship," Quarterly Journal of Economics.

Bresnahan, T., and F. Malerba (1999): "Industrial dynamics and the evolution of firms' and nations' competitive capabilities in the World computer industry," in The Source of Industrial Leadership, ed. by D. Mowery, and R. Nelson. Cambridge University Press, Cambridge.

Brusoni, S., And A. Prencipe (2001): "Unpacking the black box of modularity: technologies, products and organizations," Industrial and Corporate Change, 10(1), 179-205.

Christensen, C. M., M. Verlinden, and G. Westerman (2002): "Disruption, disintegration and the dissipition of differentiability," Industrial and Corporate Change, 11(5), 955-993.

Ciarli, T., R. Leoncini, S. Montresor, and M. Valente (2006): "Technological Competition in Modular Environments," in DRUID Summer Conference 2006 on Knowledge, Innovation and Competitiveness: Dynamics of Firms, Networks, regions and Institutions, Copenhagen. DRUID.

Dosi, G., M. Hobday, And L. Marengo (2000): "Problem-solving behaviours, organisational forms and the complexity tasks," Working Paper 2000/6, Laboratory of Economics and Management, Sant'Anna School of Advanced Studies.

Dosi, G., R. R. Nelson, and S. G. Winter (2000): The Nature and Dynamics of Organizational Capabilities. Oxford University Press, Oxford.

ERnST, D. (2005): "Limits to modularity: reflections on recent developments in chip design," Industry and Innovation, 12(3), 303-305.

Foss, N. (1993): "Theories of the firm: Contractual and competence perspective," Journal of Evolutionary Economics, 3, 127-145.

JACOBIDEs, M. J., AND S. G. Winter (2005): "The co-evolution of capabilites and transaction costs: Explaining the institutional structure of production," Strategic Management Journal, forthcoming.

Kauffman, S. A., J. Lobo, and W. G. Macready (2000): "Optimal search on a technology landscape," Journal of Economic Behavior \& Organization, 43, 141-166.

KLEPPER, S. (2002): "Firm survival and the evolution of oligopoly," RAND Journal of Economics, 33(1), 37-61. 
Klepper, S., And K. Simons (2000): "The making of an oligopoly: firm survival and technological change in the evolution of the U.S. tire industry," Journal of Political Economy, 108(4), 728-760.

Lancaster, K. J. (1966): "A New Approach to Consumer Theory," Journal of Political Economy, 74, 132-157.

LANGLOIS, R. (1992): "Transaction cost economics in real time," Industrial and Corporate Change, 1, 99-127.

Marengo, L., G. Dosi, P. Legrenzi, and G. Pasquali (2000): "The structure of problem-solving knowledge and the structure of organisations," Industrial and Corporate Change, 9, 757-788.

Nelson, R. R., and S. G. Winter (1982): An Evolutionary Theory of Economic Change. The Belknap Press of Harvard University Press, Cambridge, MA.

Nooteboom, B. (2004): "Governance and competence: How can they be combined?," Cambridge Journal of Economics, 28(4), 505-525.

Richardson, G. B. (1972): "The Organisation of Industry," The Eonomic Journal, 82(327), 883-896.

Robertson, P. L., and R. N. Langlois (1995): "Innovation, networks, and vertical integration," Research Policy, 24, 543-562.

Simon, H. A. (1969): The Sciences of the Artificial. MIT Press, Cambridge, MA.

Stigler, G. J. (1968): The Organization of Industry. Homewood.

TAYMAZ, E., AND Y. KILICASLAN (2005): "Determinants of subcontracting and regional development: an empirical study on Turkish textile and engineering Industries," Regional Studies, 39(5), 633-645.

Tushman, M., and P. Anderson (1986): "Technological discontinuities and organizational environments," Administrative Science Quarterly, 31, 439-465.

UtTerback, J., And W. Abernathy (1975): "A dynamic model of process and product innovation," Omega, 3(6), 639-656.

Valente, M. (2006): "Pseudo-NK: an Enhanced Model of Complexity," Discussion Paper mimeo, University of L'Aquila.

Williamson, O. E. (1975): Markets and Hierarchies. Free Press, New York.

(1999): "Strategy research: governance and competence perspectives," Strategic Management Journal, 20, 1087-1108. 


\section{A Tables}

Table 3. Parameters values: initialisation and benchmark configuration

\begin{tabular}{|c|c|c|}
\hline Parameter $^{a}$ & Description & Value \\
\hline $\bar{f}$ & Number of firms $x_{f}$ & 50 \\
\hline$i$ & Number of characteristics $y_{i}$ & $2 \forall f$ \\
\hline$j$ & Number of modules per characteristic $m_{j}=\breve{M}$ & $6 \forall f$ \\
\hline$M_{t=0}^{\iota}(1)$ & Number of internal modules & $\breve{M} \forall f$ \\
\hline$\aleph_{j}$ & Set of modules $m_{i, l \neq j}$ interdependent with $m_{i, j}$ & $\{1, \cdots, 6 \neq j\} \forall f$ \\
\hline$\epsilon^{p}$ & Price consumer preferences & 1 \\
\hline$\epsilon_{i}^{c}$ & Characteristics consumer preferences & 1 \\
\hline$\sigma^{d}$ & Demand smoothing parameter & $0.9 \forall f$ \\
\hline$\sigma^{m}$ & Market share smoothing parameter & $0.9 \forall f$ \\
\hline$H$ & Constant demand & 100 \\
\hline$D(1)$ & Initial demand & 150 \\
\hline$m s_{f}(1)$ & Initial market share & 0.02 \\
\hline$w_{f}$ & Firm specific labour cost & $5 \forall f$ \\
\hline$A_{f}$ & Firm specific productivity & $2.6 \forall f$ \\
\hline$\underline{p}_{f, j}(1)$ & Initial input cost & $5 \forall f$ \\
\hline$\underline{D}_{f, j}(1)$ & Initial demand for each component & $0 \forall f$ \\
\hline$\nu_{f}$ & Firm specific mark-up on unitary input costs & $0.1 \forall f$ \\
\hline$\kappa$ & Defines the width of the Normal function for the computation of $m_{i, j} \mathrm{~s}$ & $-2 \forall f$ \\
\hline$b_{f, j}$ & $\begin{array}{l}\text { Unitary price of inputs, after innovation/internalisation /on/of com- } \\
\text { ponent } j\end{array}$ & $5 \forall f$ \\
\hline $1-\sigma^{p}$ & Speed at which learning reduces the cost of internalised components & $0.05 \forall f$ \\
\hline$\theta$ & Economies of scale & $0.12 \forall f$ \\
\hline$\delta$ & Maximum innovation step (mutation of a module position) & $0.05 \forall f$ \\
\hline$\xi_{i, j}(1)$ & Initial value of $\xi_{i, j}$ & $R N D(98,102) \forall f$ \\
\hline$\alpha_{i, j}$ & Contribution of $m_{i, j}$ s to $y_{i}$ & $R N D[0.1,0.9]_{\square}^{b} \forall f, i$ \\
\hline $\bar{\mu}(1)$ & Initial value of the technological frontier & $100 \forall j$ \\
\hline$a_{i, j, l \neq j}$ & Relation between two interdependent modules $j$ and $l$ in affecting $m_{i, j}$ & $R N D(-1,1){ }^{c} \forall f$ \\
\hline$v$ & Random change in the technological frontier & $\sim U[0,1] \forall f$ \\
\hline$\omega$ & Magnitude of increase of the technological frontier & Table 4 \\
\hline$Z$ & Pace of increase of the technological frontier & Table 4 \\
\hline$\gamma$ & $\begin{array}{l}\text { Maximum technological difference between buyer and supplier when } \\
\text { a component is outsourced }\end{array}$ & $0.05 \forall f$ \\
\hline$\varpi$ & $\begin{array}{l}\text { Number of positive attempts required before undergoing an organisa- } \\
\text { tional change }\end{array}$ & $5 \forall f$ \\
\hline
\end{tabular}

${ }^{a}$ Into parenthesis the number of lags of the initial value for lagged variables.

${ }^{b}$ Average value is 0.33210 .

${ }^{c}$ Given that firms produce the same good, they all have the same interaction structure between components (each module interacts with the remaining five). Average of $|a|=0.46082$; $\operatorname{Min}(a)=-0.86632 ; \operatorname{Max}(a)=0.86087$. See Figure 7 for the distribution of a's. 
Table 4. Organizational dynamics and technological change: average number of integrated modules

\begin{tabular}{|c|c|c|c|}
\hline & \multicolumn{3}{|c|}{ Technological frontier dynamics } \\
\hline & & Large & Small \\
\hline & & $\omega=0.1$ & $\omega=0.001$ \\
\hline \multirow{3}{*}{$\begin{array}{l}\text { Non-innovative } \\
\text { intermediate } \\
\text { sellers }\end{array}$} & Frequent $Z=0.5$ & low dis \& & mid dis \& \\
\hline & & long waves & small treq cycles \\
\hline & Infrequent $Z=0.01$ & $\begin{array}{c}\text { mid dis \& } \\
\text { large \& freq cycles }\end{array}$ & $\begin{array}{l}\text { mid-high dis \& } \\
\text { stable ind. str. }\end{array}$ \\
\hline \multirow{2}{*}{$\begin{array}{l}\text { Innovative } \\
\text { intermediate } \\
\text { sellers }\end{array}$} & Frequent $Z=0.5$ & $\begin{array}{c}\text { low dis \& } \\
\text { small freq cycles }\end{array}$ & $\begin{array}{c}\text { high dis } \\
\text { smoothly incr. }\end{array}$ \\
\hline & Infrequent $Z=0.01$ & $\begin{array}{c}\text { high dis \& } \\
\text { incr. infreq jumps }\end{array}$ & $\begin{array}{l}\text { high dis \& } \\
\text { stable ind. str. }\end{array}$ \\
\hline
\end{tabular}

\begin{tabular}{|c|c|c|c|}
\hline \multirow{3}{*}{ Key: } & \multicolumn{2}{|c|}{${ }_{\text {Disintegration degree }}^{a}$} & \\
\hline & High: & 1-2.5 internal modules & Benchmark case \\
\hline & Low: & 4-6 internal modules & \\
\hline
\end{tabular}

${ }^{a}$ Total modules (product components) $=6$ 


\section{B Figures}

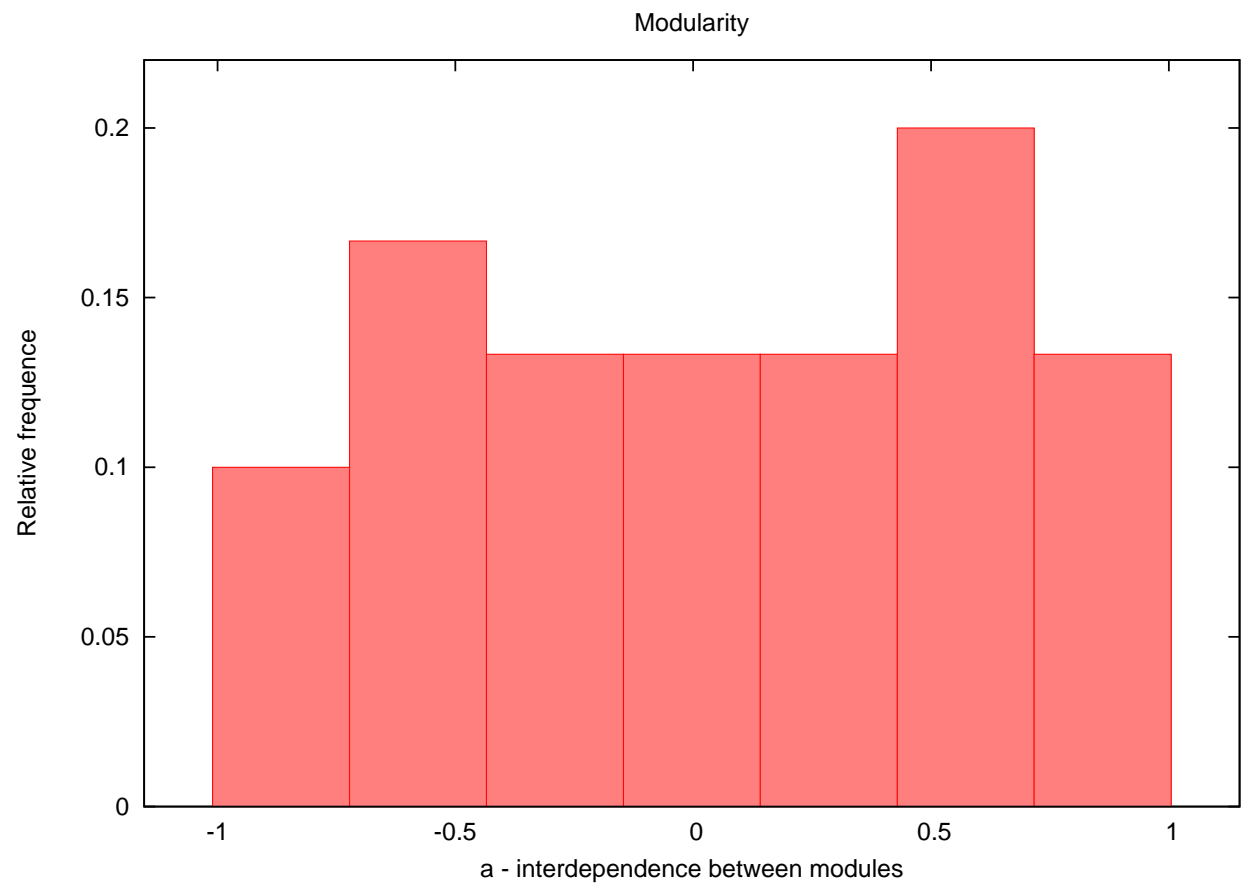

Figure 7: Distribution of a's, the values of interdependence (non-modularity) between product components 


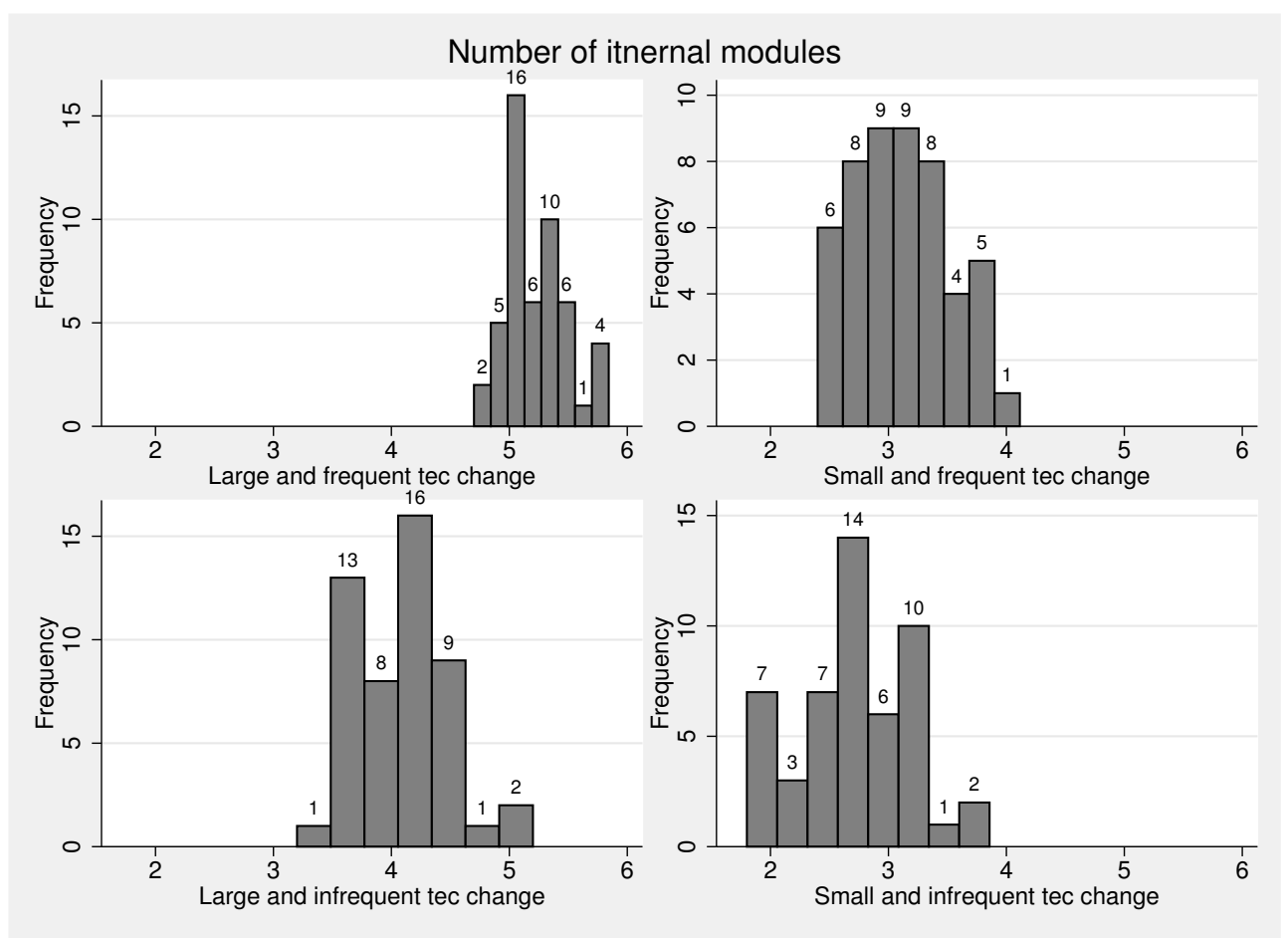

Figure 8: Cross-firms distribution (histograms) of the number of integrated components in the last period of the simulation $(t=10000)$ : the four technological environments.

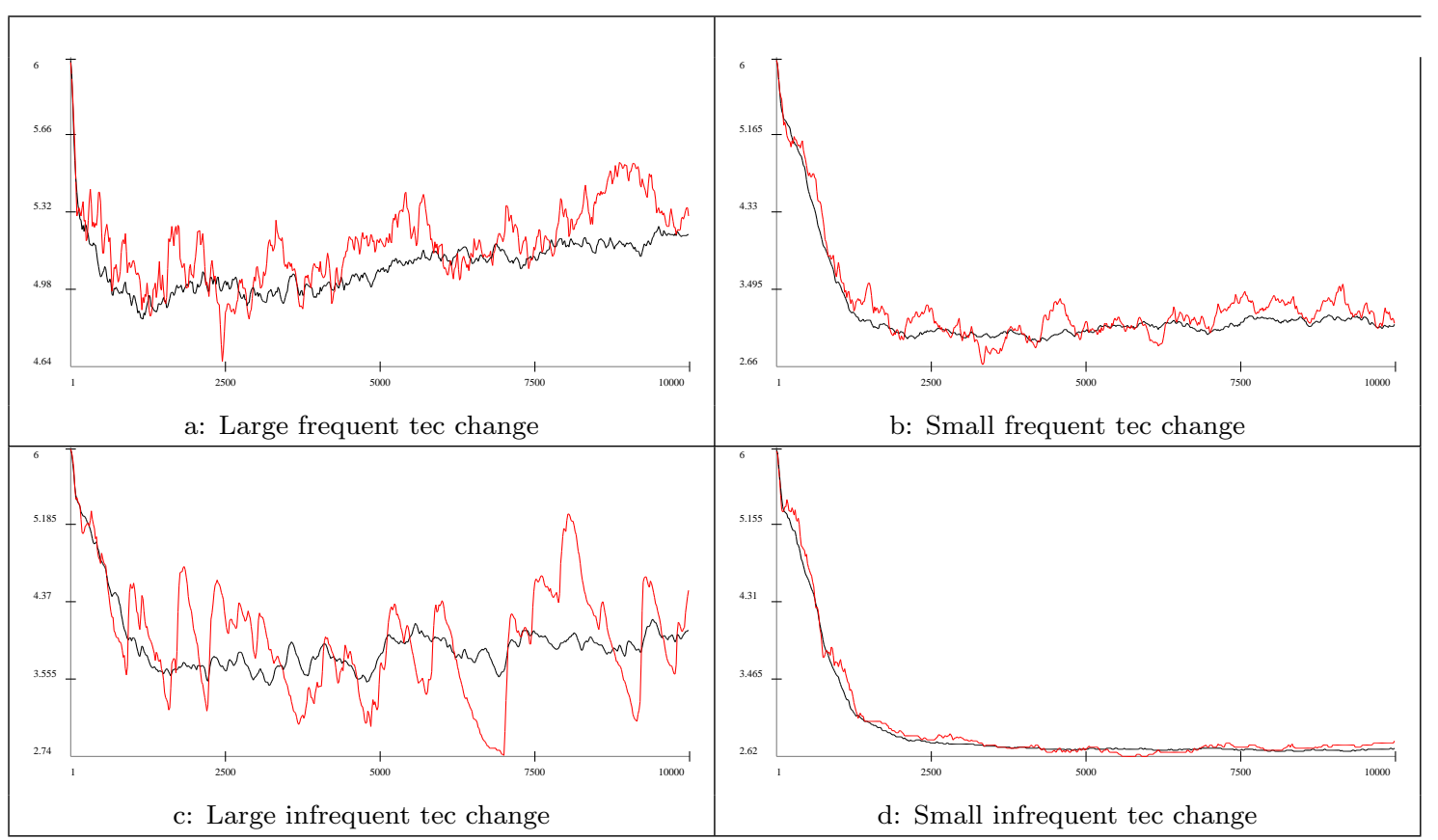

Figure 9: Evolution of the average number of integrated components (modules) (all environments): one simulation run (red) and cross-simulations average (black) 


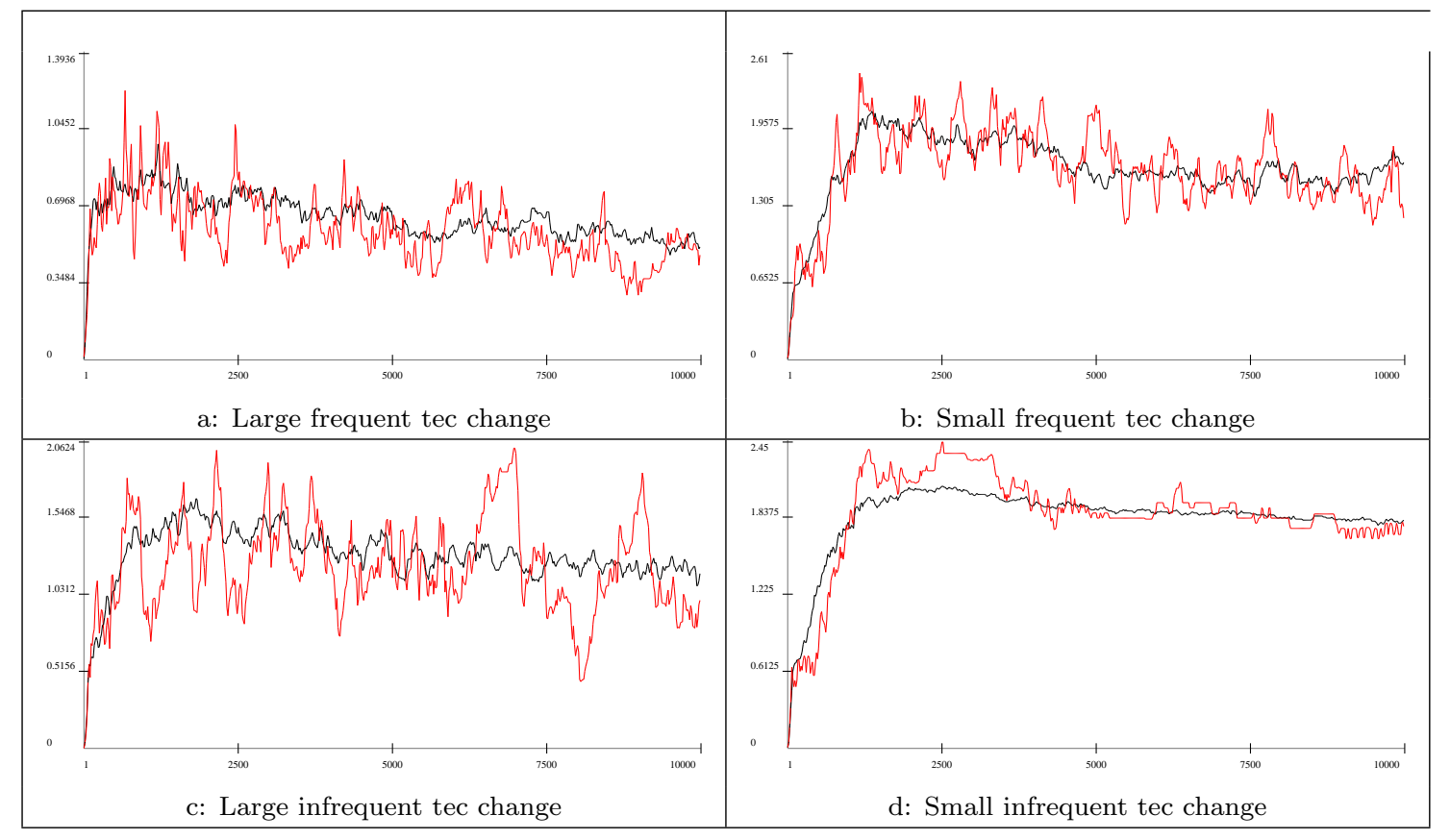

Figure 10: Evolution of the variance of the number of integrated components (modules) (all environments): one simulation run (red) and cross-simulations average (black)

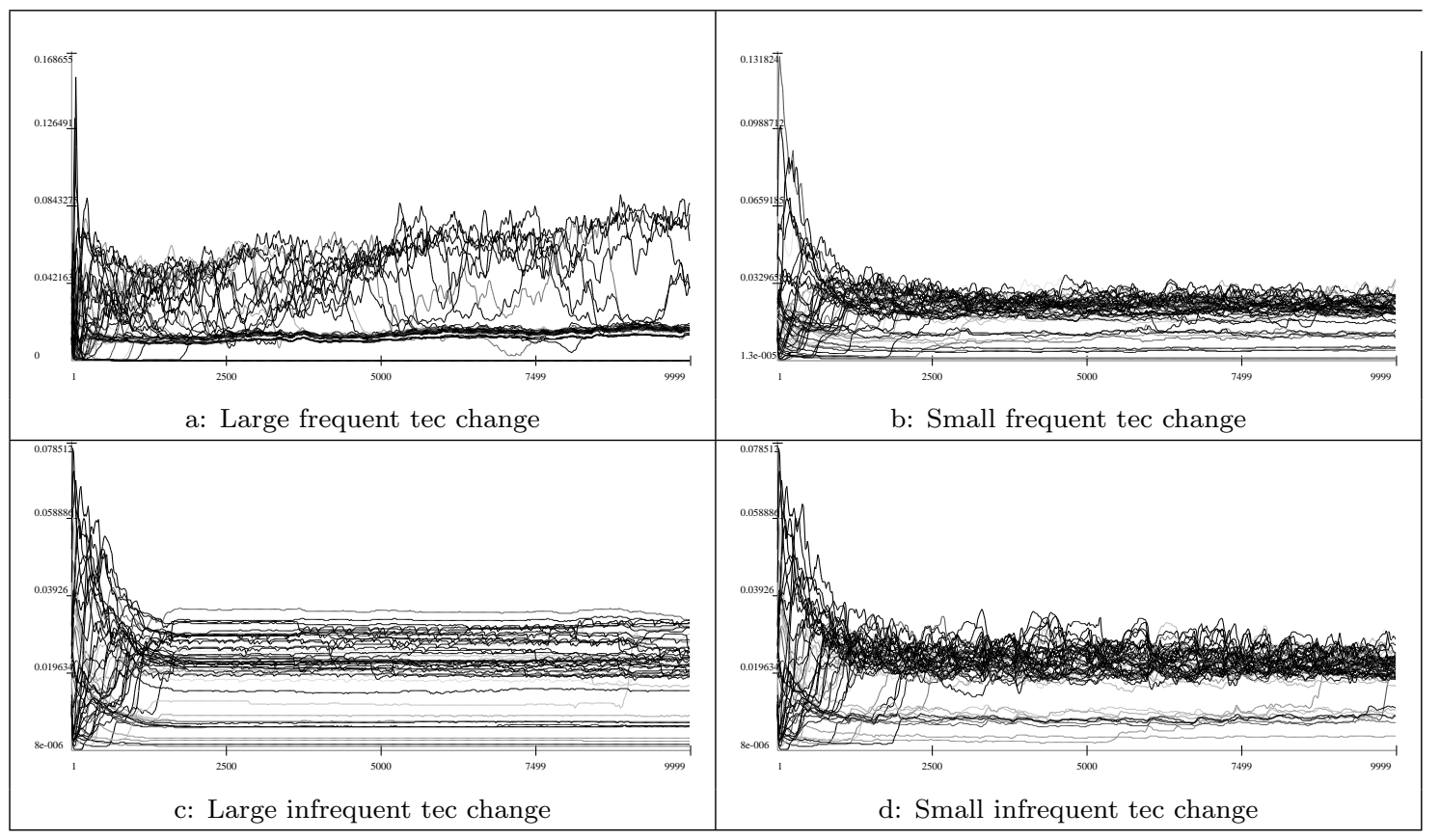

Figure 11: Evolution of consumable producers market shares (the four environments): one simulation run 